\title{
Flow mechanism and simulation approaches for shale gas reservoirs: A review
}

\author{
Tao Zhang ${ }^{1}$ Shuyu Sun ${ }^{1 *}$ Hongqing Song ${ }^{1,2 *}$ \\ ${ }^{1}$ Computational Transport Phenomena Laboratory(CTPL), Division of Physical Sciences and Engineering (PSE), \\ King Abdullah University of Science and Technology (KAUST), Thuwal 23955-6900, Kingdom of Saudi Arabia \\ ${ }^{2}$ School of civil and resource engineering, University of Science and Technology Beijing,
}

30 Xueyuan Rd, Beijing 100085, People's Republic of China

\begin{abstract}
The past two decades have borne remarkable progress in our understanding of flow mechanisms and numerical simulation approaches of shale gas reservoir, with much larger the number of publications in recent five years compared to that before year 2012. In this paper, a review is constructed with three parts: flow mechanism, reservoir models and numerical approaches. In mechanism, it is found that gas adsorption process can be concluded into different isotherm models for various reservoir basins. Multi-component adsorption mechanism are taken into account in recent years. Flow mechanism and equations vary with different Knudsen number, which could be figured out in two ways: Molecular Dynamics (MD) and Lattice Boltzmann Method (LBM). MD has been successfully applied in the study of adsorption, diffusion, displacement and other mechanisms. LBM has been introduced in the study of slippage, Knudsen diffusion and apparent permeability correction. The apparent permeability corrections are introduced to improve classic Darcy's model in matrix with low velocities and fractures with high velocities. At reservoir scale simulation, gas flow models are presented with multiple-porosity classified into organic matrix with nanopores, organic matrix with micropores, inorganic matrix and natural fractures. A popular trend is to incorporate geomechanism with flow model in order to better understand the shale gas production. Finally, to solve the new models based on enhanced flow mechanisms, improved macroscopic numerical approaches, including the finite difference method (FDM) and finite element method (FEM) are common used in this area. Other approaches, like finite volume method (FVM) and fast matching method(FMM) are also developed in recent years.
\end{abstract}

\section{Introduction}

2 Shale gas reservoir is playing an growing important role in the world energy market, 3 due to its significant advantages of less pollution in combustion compared with con4 ventional fuel resources like oil and coal. Starting from the beginning of 21st century

\footnotetext{
${ }^{*}$ Corresponding authors: shuyu.sun@kaust.edu.sa, songhongqing@ustb.edu.cn
} 
[1-4], shale gas exploitation has become an essential component to bridge the growing gap between domestic production and consumption and thus secure the energy supply in North America. [5] The United States successfully became the largest natural gas producer in 2009, thanks to the high progress in shale gas production. [6, 7] In another large energy exporter, shale gas resources in Canada are estimated with an amount larger than 1000 tcf (tera-cubic cubic feet). A paradigm shift has been made toward the exploration of shale gas in one of the main reservoir block, the Western Canada sedimentary basin (WCSB). [8, 9] With the development and popularity of shale gas exploration all over the world, there have also been other countries and areas reported with great potential of exploitation. For example, shale gas resources in China are estimated about $31 \times 10^{12} m^{3} \cdot[10]$

Properties of shale gas reservoir are essentially needed for successful estimation and extraction. As a result, accurate characterization and detailed description of reservoirs should be considered as the prior purpose of relevant researches. Due to the complex hydraulic and thermal reservoir environment in production, it is hard to reproduce the same process in laboratory. Thus, numerical simulation has been a popular trend in the study of unconventional shale gas reservoirs. After a quick investigation on Web of Science Core Collection, it is found that published papers related with shale gas numerical simulation has been greatly increased, as shown in Fig.1. A significant increase could be found from 2012, and continues increasing until now.

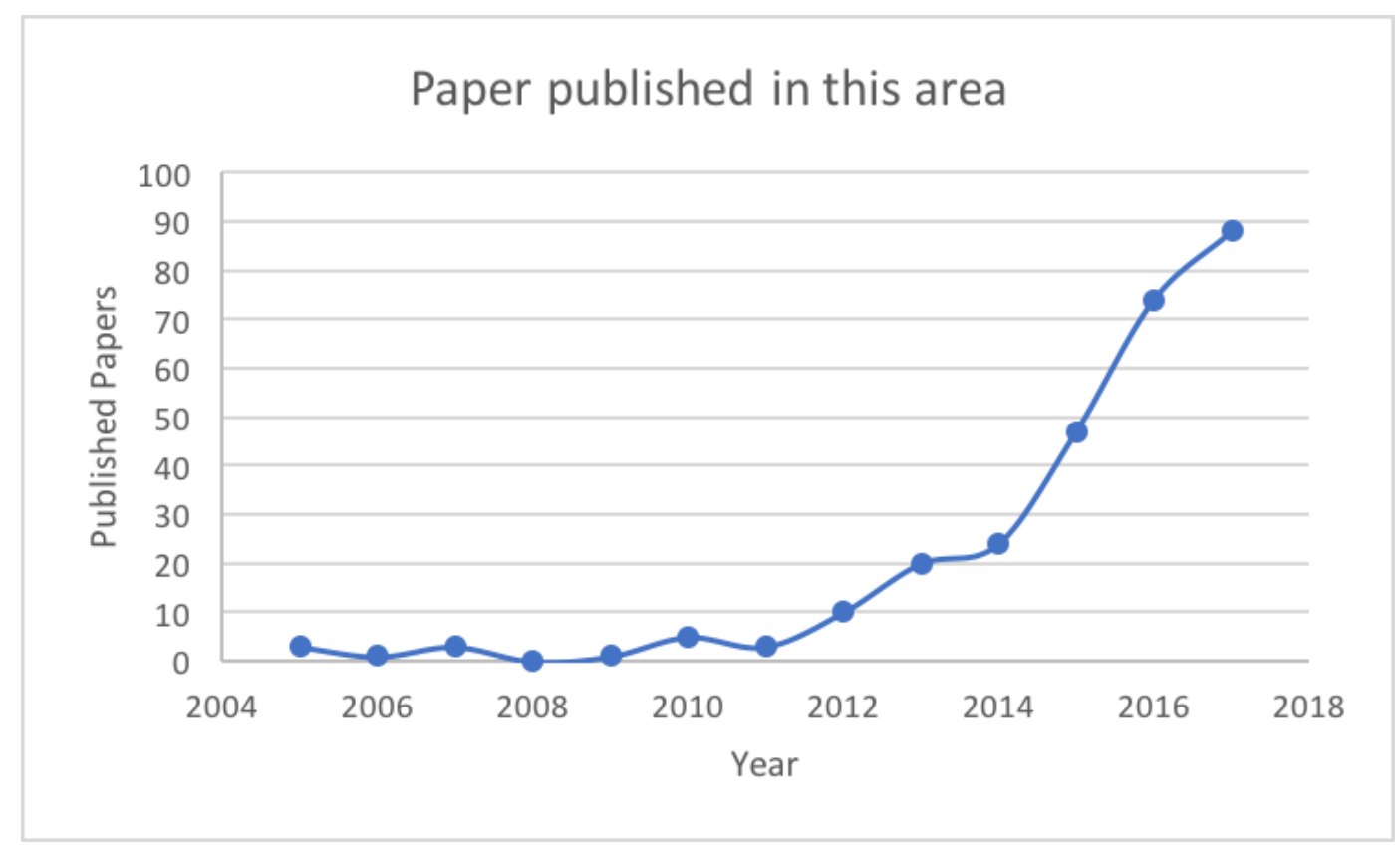

Fig. 1 Paper numbers related with shale gas numerical simulation on Web of Science in recent years 
while, apparent permeability correction, which is the macroscopic focus, is concluded. Afterwards, we focus on the gas flow simulations at reservoir scales, including numerical models and the effect of geo-mechanics. Finally, the common macroscopic numerical simulation approaches, including finite element method, finite difference method and other schemes, will be presented.

\section{Flow mechanism of shale gas}

Permeability is always relatively low in shale gas reservoirs, generally less than $1 \mathrm{md}$, and stratigraphic composition can be divided into different types of intervals (e.g., Devonian, Jurassic, and Cretaceous strata). [11, 12] The stress-sensitive parameters, including organic richness, porosity, thickness, and lateral extent can vary significantly with in-situ stress changes. Consequently, the fluid flow and geomechanics impacts are always effected by the change. [13] Such extremely tight rock formations in shale gas reservoirs with different parameters result in the gas transportation occurs through them by different mechanisms. With more efforts been devoted to the researches of such flow mechanisms, the inherent limitations of the conventional macroscopic methods used in petroleum industry are been overcomed and new microscopic and mesoscopic approaches including Molecular Dynamics (MD) and Lattice Boltzmann Method (LBM) are introduced.

\subsection{Adsorption/desorption mechanism}

There are three states of gas reserved in shale reservoir: free gas, adsorbed gas and dissolved gas. [14] In previous study, it is found that adsorbed gas is the main state among the above three states, with statistical results indicating that $20 \%-80 \%$ of the total gas is adsorbed in reservoirs. [15-18] Adsorption properties can provide critical information to help characterize shale structures and optimize hydraulic fracturing. With the decrease of environment pressure, adsorbed gas will become free gas in the early period of exploitation. [19] As a result, gas adsorption/desorption description is of great importance to investigate the well production.

Plenties of work have been conducted to study the methane adsorption mechanisms. [20-25] In some studies, molecular accumulation is viewed as the main origin of adsorption on shale surface. It is the consequence of the minimization theory of surface energy. [22] Meanwhile, potential theory is sometimes used to identify the adsorption process, with van der Waals forces leading to physisorption. [24, 25] Besides, properties including pressure, temperature and geological characteristics have also caused much attention recently on how to affect the adsorption capacity. [22, 23] TOC content, which is short for total organic carbon, is found of high relevance with adsorption capacity. Generally speaking, samples with high TOC content will present high values of contents including total cumulative pore volume, surface area and total porosity, which directly lead to a higher adsorption capacity than the sample with less TOC. Compared with other rocks, 
shale contains high organic matter, which results in a high gas adsorption amount.

Shale permeability will be changed, due to the desorption of gas in the production process. [26] For example, gas desorption process is found in organic grids, known as kerogen, where pressure drop occurs. [27] Meanwhile, pressure difference will be generated between the bulk matrix and the pores, with the pore pressure decreasing in the free gas production process, thus the desorption on the surface of bulk matrix is reinforced.

A large number of gas adsorption isotherm models have been proposed in previous studies, such as Langmuir's type model, Freundlich type model, Langmuir-Freundich type model, D-R type model, BET type model and Toth type models. [28-36]. Most available adsorption models, including their basic equation and the basins where they are applied are listed as Table 1 . In this table, $V$ denotes adsorbate volume, $P$ denotes pressure, $K$ denotes an associated equilibrium constant, $k$ denotes Henry's constant, $b$ denotes the adsorption affinity, $D$ denotes the empirical binary-interaction parameter, $x$ and $m$ denotes a constant for a given absobate and absorbent at a particular temperature and $c$ is a constant related to the adsorption net heat. All the subscript $L$ in $P_{L}$ and $V_{L}$ denotes the Langmuir pressrue and Langmuir volume.

Table 1 The comparison of different isotherm adsorption models

\begin{tabular}{|c|c|c|c|}
\hline Classification & Isotherm model & Basin & Ref \\
\hline \hline Langmuir & $V=\frac{V_{L} P}{P_{L}+P}$ & Barnett, the USA & {$[29,37]$} \\
\hline Freundlich & $V=K p^{x}$ & Mansouri, Iran & {$[28,38]$} \\
\hline Langmuir-Freundlich & $V=\frac{V_{L}(b p)^{m}}{1+(b p)^{m}}$ & Longmaxi, China & {$[36,39,40]$} \\
\hline D-R & $V=V_{0} \exp \left[-D n^{2}\left(P_{s} / P\right)\right]$ & Qaidam, China & {$[41]$} \\
\hline BET & $n_{a}=\frac{1}{\frac{1}{n_{o} c}+\frac{c-1}{n_{o} c} \frac{P}{P_{0}} \frac{1}{P_{o}}-1}$ & Marcellus, the USA & {$[30,42]$} \\
\hline Toth & $V=\frac{V_{L} b p}{\left[1+(b p)^{k}\right] 1 / k}$ & Bornholm, Denmark & {$[35,43]$} \\
\hline
\end{tabular}

Among the above models, The Langmuir's type model is always considered as the simplest and most effective. [44] With its long history and wide application, model parameters have been reasonably explained and different evaluated models have been proposed based on the original equation. This large set of enhanced models have been used for describing methane and other gas adsorption behaviors with satisfactory performance. [45-47] For example, a widely used evaluated form of Langmuir isotherm is given by:

$$
q=\frac{\rho_{s} M_{g}}{V_{s t d}} q_{a}=\frac{\rho_{s} M_{g}}{V_{\text {std }}} \frac{q_{L} P}{P_{L}+P}
$$

where $\rho_{s}\left(\mathrm{~kg} / \mathrm{m}^{3}\right)$ denotes the material density of the porous sample, $q\left(\mathrm{~kg} / \mathrm{m}^{3}\right)$ is the mass of gas adsorbed per solid volume, $q_{a}\left(\mathrm{~m}^{3} / \mathrm{kg}\right)$ is the standard volume of gas adsorbed per solid mass, $q_{L}\left(\mathrm{~m}^{3} / \mathrm{kg}\right)$ is the Langmuir gas volume, $V_{\text {std }}\left(\mathrm{m}^{3} / \mathrm{kmol}\right)$ is the molar volume of gas at standard temperature $(273.15 \mathrm{~K})$ and pressure $(101,325 \mathrm{~Pa})$, $p(P a)$ is the gas pressure, $p_{L}(P a)$ is the Langmuir gas pressure, and $M_{g}(\mathrm{~kg} / \mathrm{mol})$ is the molecular weight of gas. 
In reservoir scale, the effect of gas adsorption capacity are highly extrapolated in regions. As a result, gas in place evaluation and production prediction are quite easy to be overestimated or underestimated and then severely impact the energy industry and social economy. $[48,49]$ However, the existing models are still in developing and continuous optimization. For example, the original BET model is seldom used at present due to the weak theoretical foundations. It has been found that some assumptions in these models, like multilayer formation, small pore capillary condensation, adsorbed liquid phase and saturation pressure, are no longer suitable for special flow mechanisms of shale gas fluid. [50,51] Another shortcoming of the classical model is that extrapolated data beyond the test range cannot be fully relied due to different empirical correlations in different temperature regimes. The original physical meanings inside these models, coming from the well-designed experiments, are weakened due to the introduction of some empirical constants. These constants are manually corrected to improve the fitting performance but make the models less reliable. [44] There remains a lot to do to meet the realistic industry conditions better and to help the industry with more accuracy on the production forecast and control.

It has been pointed out that gas-in-place voumes in reservoirs are often incorrectly determined for cases with multi-component sorbed gas phase. [52-54] Especially for shale gas fluid flow with high composition of varieties of hydrocarbons $(\mathrm{C} 2+)$ and subsequently high total organic content (TOC), the adjustment of taking multi-component effect into account has been more necessary in the gas-in-place predictions. Compared to conventional approach, the new multi-component model will show a 20 per cent decrease in total gas storage capacity calculations. [52] Besides, multi-component sorption phenomena, in particular in the primary (micro-) pore structure of the shale matrix, e.g., co- and counter diffusion and competitive adsorption process are the fundamental interests in the study of $\mathrm{CO}_{2}$ sequestration and enhanced shale gas recovery. [54] However, the current multi-component adsorption model are still limited on just modifications based on classical single-component Langmuir sorption model. [53, 55] A more uniform and widely applicable model is still in urgent requirement to meet the complex physical and chemical environment of shale gas reservoirs. With the rapid development of fully coupled multi-component multi-continuum compositional simulator which incorporates several transport/storage mechanisms of shale gas reservoirs, a more comprehensive adsorption/desorption model is needed to capture and predict the transport process in shale gas reservoirs.

\subsection{Flow mechanisms of gas transport in shale gas reservoir}

It is important to study the flow mechanism of gas transport in shale gas reservoir. Particular interest have been focused on the multi-scale flow simulation on the subsurface porous media with pore size ranging from macro-scale $(>1 \mathrm{~mm})$ to nanoscale $(<100 \mathrm{~nm}) .[56,57]$ Different pore scale characteristics are presented with different flow regimes identified by Knudsen number. [58-61] Slippage and diffusion processes are 
often viewed as the main flow mechanisms.[62] New approaches, including Molecular Dynamics (MD) and Lattice Boltzmann Method (LBM), are rapidly developed in these years to study the flow mechanisms.

\subsubsection{Flow regime}

Knudsen number $(K n)$ is a parameter introduced in gas flow description to identify flow regimes with different rarefaction degree of gas encountered. Generally, four regimes are characterized based on $K n$ : continuous flow $\left(K n<10^{-3}\right)$, slip flow $\left(10^{-3}<K n<\right.$ $\left.10^{0.1}\right)$, transition flow $(0.1<K n<10)$ and Knudsen flow $(K n>10)$. [63] Different interfacial effects are found effective in different flow regimes in small porous structure. For large tube diameter, the gas flow is mainly viewed as continuous flow with only slip regime near the wall. [64] Strong interfacial effects are found in shale nanotubes, which is believed to be caused by two important flow regimes including Knudsen flow and transitional flow. It should be noted that the flow pattern of single gas flow and gas-water two phase flow is of big difference. [65] In this paper, we focus on the single phase flow.

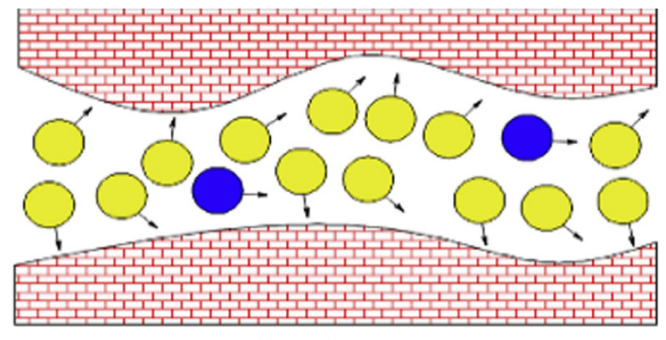

$\mathrm{Kn}>10$

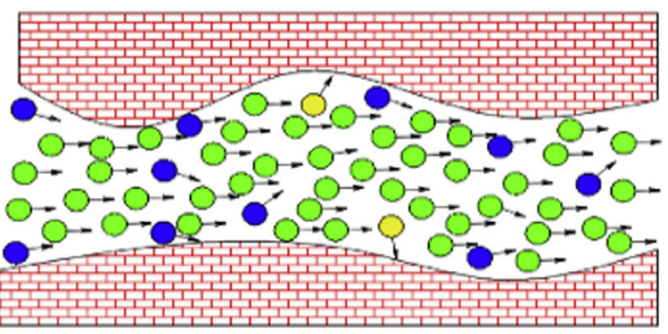

$0.01<\mathrm{Kn}<0.1$

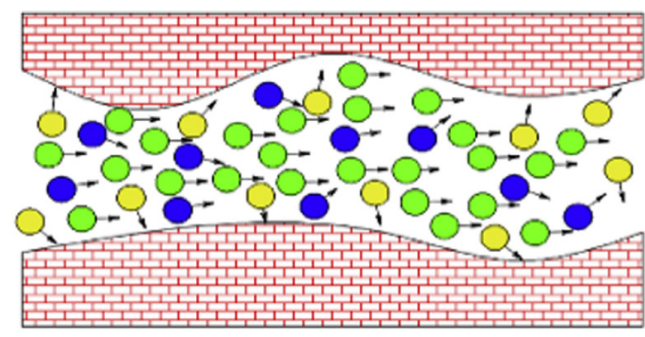

$0.1<\mathrm{Kn}<10$

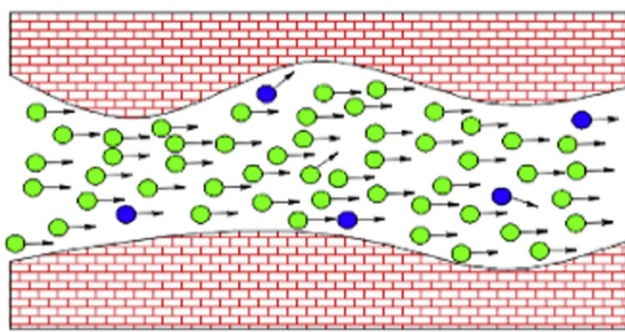

$\mathrm{K} n<0.01$

Fig. 2 Schematic diagram of shale gas transport mechanism with different flow regimes[66]

A main usage of flow regime characterization is that different governing models, resulting in different simulation approaches are corresponding to the Knudsen number and flow regimes. Table 2 shows the gas flow regimes and corresponding governing equations along with boundary conditions. When $K n$ varies from 0.001 and 0.1 , gas transportation is in the regime of slip flow, slip boundary condition should be incorporated into Navier-Stokes equation or Lattice-Boltzmann method (LBM) to take into account the slippage on the gas solid interface. When $K n$ is in a higher range of 0.1 and 10, gas flow enters the transitional regime, where neither Navier-Stokes equation 
nor lattice-Boltzmann model is applicable any more. Then, Burnett equation based on higher order moments of Boltzmann equation should be solved or numerical method of direct simulation Monte Carlo (DSMC) should be used to represent the fluid flow behavior. As Kn goes beyond 10, gas stream is considered as free molecules, and Molecular Dynamics (MD) must be adopted to capture the physics controlling the gas flow.

Table 2 Knudsen number and flow regimes with applicable mathematical models

\begin{tabular}{|c|c|c|c|c|}
\hline Particle model & \multicolumn{3}{|c|}{ Boltzmann equation (BE) } & Collisionless BE \\
\hline \hline Continuum model & \multicolumn{2}{|c|}{ LBM/NS equation } & DSMC & Molecular Dynamics \\
\hline$K_{n}$ & $(0,0.001)$ & $(0.001,0.1)$ & $(0.1,10)$ & $>10$ \\
\hline Flow regimes & No slip & Slip & Transitional & Free molecular \\
\hline
\end{tabular}

For gas flow in nanotubes, it has been demonstrated that slippage effects will change the flow regime identification. [67] The concept of slip has a long history, starting from the famous scientist Navier $[68,69]$, and has been used in a large range of practices. For fluid flow passing rough surface, slip boundary condition is often applied with the slip-length relevant to roughness height. When $K n<10^{-2}$, flow is in continuous regime and Darcy's law is enough to describe the flow. As $K n$ increases from 0.01, diffusive flux is no longer ignorable and additional term should be considered in the flow equations, which makes it nonlinear.

To correct the permeability with consideration of gas slippage effect, Klinkenberg approach is often applied in previous studies. [70,71] For example, to handle flow in all the four flow regimes, a new equation is proposed in [70,72,73], with the gas slip factor modified based on the dusty-gas model:

$$
v=-\left(\frac{D}{p}+\frac{k}{\mu}\right) \nabla p
$$

A comprehensive model capable of handling gas flow through multi-scale porous media varying from nanoscale to macro-scale is generated based on the above equation, with the prospective of molecular kinetics. [74] Knudsen diffusion process is often considered as driven by collisions of wall with molecule and collective diffusion process is driven by collision of molecule with molecule. In the new formulation, the collision coefficient is determined based on the consideration of both Knudsen and collective diffusion.It is figured out that for single phase fluid flow in nanotubes, the interfacial effects existed in the wall surface will lead to form a thin liquid film and the flow characteristics will be changed then. [75] The stress singularity is removed in thin film theory, and fluid front is thought to move over dry surface. It has been shown in previous simulations that separations of about ten molecular diameters down will be resulted in the fluid viscosity with the bulk value. [68] There has also been assumptions [76, 77] that the formed gas film has a thickness between the molecular size and the gas mean free path. Molecular dynamics simulation has proved that Myer's model is correct. [78]

Geometrical properties of fractured porous media is vital to predict and evaluate the hydraulic transport properties of fracture networks. [79, 80] Although a variety of 
subjects have been studied related to geometrical, fractal and hydraulic properties of fractured porous media such as rock masses and reservoirs, a gap still exists between theoretical knowledge and field practice. [81] It is of great importantce to seek new theoretical and numerical studies and advances in various subjects addressing flow and transport mechanism as well as hydrocarbon recovery improvement, such as innovative stimulation techniques, reservoir characterization, and other approaches. Specifically, not all the length distribution of fractures and fracture networks are follows the fractal law. They may be multi-fractal, and even non-fractal. Thus, more elaborate explorations are need for adequately characterizing the complex fractured networks. As we discussed in above section, fractal dimension is one of most important parameters to quantitatively characterize the complexity of fractures. However, fractal dimension is sensitive to prediction methods, even some irrational values may be obtained. [82] Future works also should be focused on the influence of fracture surface roughness, hydraulic gradient, the coupled thermo-hydro-mechanical-chemical processes.

\subsubsection{Molecular dynamics for shale gas transportation}

Molecular dynamics (MD) simulation approaches recognize the fluid flow as a swarm of discrete particles and is suitable for flow simulation with high $K n$ number. It is often seen as an accurate approach due to the deterministic [83] or probabilistic [84] calculation of the particle properties at every time steps. $[83,85,86]$ These properties include particle inertia, position and state. Boltzmann distribution is often used to describe individual particle dynamics at different temperatures. Newton's equation of motion is integrated numerically to determine the two-body potential energy and transient evaluation of two particles and then to find the particle positions.

A general purpose of using MD simulation is to investigate the adsorption and desorption (displacement) process of shale gas flow. [87-89] Some researchers have performed numerous studies using molecular dynamic simulations to model gas flow through a single nanotube, in which the interface microstructure phenomenon is of special interest [90]. The results have shown that the interactions between fluid and solid wall is a great cause of flow promotion. Meanwhile, MD studies have been performed to understand the shale gas diffusion process in special pores [91] and study thermodynamical properties of gas transport in montmorillonite (MMT). [92, 93] MD studies are also carried out to help describe the pore structures in shale formations [94] and it can also be used in the general gas recovery process. [95] In Table 3, we listed five recent papers with high citing rates relevant to molecular dynamics simulation of shale gas reservoirs. The citations of each paper is searched from Web of Science Core Database.

Table 3 Five high-citing papers of MD simulation of shale gas reservoirs 


\begin{tabular}{|c|c|c|c|c|}
\hline Authors & Year & Interest & Ref & Cited by \\
\hline Sharma, et al & 2015 & Adsorption/Diffusion & {$[87]$} & 35 \\
\hline Zhehui, et al & 2015 & Molecular velocity in nanopores & {$[88]$} & 22 \\
\hline HengAn, et al & 2015 & Adsorption/Displacement & {$[89]$} & 30 \\
\hline Mahnaz, et al & 2014 & Pore size distribution & {$[94]$} & 49 \\
\hline Quanzi, et al & 2015 & Enhanced recovery & {$[95]$} & 26 \\
\hline
\end{tabular}

It should be noted that, modern computation capability, represented by supercomputers, is still not enough to handle a reasonable, practical and very detailed flow simulation through nanotubes network in time and space scale of the real production process in shale gas reservoir. Although MD models are designed to capture microscopic interactions, which is the foundation of macroscopic phenomenons, time steps are generally strictly limited to femtoseconds $\left(10^{-15} \mathrm{~s}\right)$, which results in the limitation of simulation time scale generally ranging from picoseconds $\left(10^{-12} \mathrm{~s}\right)$ to nanoseconds $\left(10^{-9} \mathrm{~s}\right)$. [83]

\subsubsection{Lattice Boltzmann Method}

The Lattice Boltzmann Method (LBM) has been proved to be a useful and efficient approach to study the shale gas reservoirs. [96, 97] Knudsen diffusion has already been incorporated in the general LBM flow models to describe transport properties of shale gas fluid flows. [96] For multiphase flow, the famous Shan-Chen model of single-component multiphase flow is common used. [97]

The first attempt to take Knudsen diffusion into account of the fluid flow using LBM simulation approach is said to be in [97]. In their study, compared to common used shale tortuosity, which is an important component of Bruggeman equation, the improved model will lead to a much higher tortuosity result and consequently the intrinsic permeability is said to be extremely lower. [97] For relative permeability, it is found that the countercurrent relative permeabilities, as a function of wetting saturations, usually seem smaller than the cocurrent ones with a Lattice Boltzmann scheme derived for two phase steady-state flow. [98]

Characteristics of gas flow in organic nano-pores in shale gas reservoirs can be evaluated effectively using developed LBM simulation. Under assumptions of small Knudsen number, flow properties simulated with LBM models agree well with the classical macroscopic Poiseuille's law. Flow capacity, or flow rate, is found to be proportional to the square of pore size. [96] However, the relaxation time used in LBM models should be corrected to cover simulations at high $K n$ value. Permeability is increased as the result of velocity enhancement caused by slippage effect on pore walls. Adsorptive and cohesive forces among particles in gas fluid flow is used to simulate molecular level interactions accounting with LBM scheme in [99]. With slip boundary condtion of Langmuir type at organic pore walls, mass transport along the tube walls is partitioned into two components: hopping of adsorbed gas molecules and slippage of free gas molecules. Hopping is the process of surface transport. In Table 4, we listed five recent papers with high citing 
rates relevant to lattice boltzmann simulation of shale gas reservoirs. The citations of each paper is searched from Web of Science Core Database.

Table 4 Five high-citing papers of LBM simulation of shale gas reservoirs

\begin{tabular}{|c|c|c|c|c|}
\hline Authors & Year & Interest & Ref & Cited by \\
\hline \hline Chen, et al & 2015 & Knudsen diffusion & {$[97]$} & 70 \\
\hline Fathi, et al & 2012 & Slippage and hopping & {$[99]$} & 24 \\
\hline XIaoling, et al & 2014 & Apparent permeability & {$[96]$} & 31 \\
\hline Ebrahim, et al & 2012 & Klinkenberg effect & {$[100]$} & 58 \\
\hline Song, et al & 2015 & Gas flow rate & {$[101]$} & 13 \\
\hline
\end{tabular}

Previous researches have shown that approaches belonging to Lattice Boltzmann scheme are still limited in the application of rapidly recovering the imaging of pore structure and furthermore in the simulaiton and visulization of fluid flow in porous media, especially less effective in 3 dimensions. Pore-network models, which is also a meso-scopic approach, is capable of simplifying detailed large scale pore structures into a readable network constituting of pore bodies connected by pore throats. [102105] Each pore body is associated with different number of attributes, which is called coordinates numbers, and the spatial location is then specified explicitly. In this way, the highly irregular porous space is reduced to a network with topology and geometry easy captured. [4]

\subsection{Apparent permeability correction}

A standard approach to study gas transpotation in porous media is the famous Darcy's law. [106] In this theory, the average macroscopic gas velocity $v$ is assumed to be determined by global permeability $k$ and the pressure gradient $\nabla p$ across the media

$$
v=-\frac{k}{\mu} \nabla p
$$

where $\mu$ is the gas viscosity. The permeability $k$ is a macroscopic parameter defined to describe the relation between gas flow and pore structure. Same as many other classical macroscopic theories, Darcy's law was first concluded from experiments conducted by Darcy [106]. It is proved that Darcy's law can also be derived from Navier-Stokes equation as a simplification and extension in porous media. [70].

However, the long history research of shale gas reservoir have brought insights of special percolation characteristics and flow mechanisms in the tight rock structures. The original Darcy's equation is no longer capable of explaining these phenomenons. A strict limitation of flow velocity is found in the application of classical Darcy's law. For highly fractured reservoir structures, gas flow is at relatively high velocity and the original Darcy's law will lead to misleading results, sometimes with an over prediction of productivity as much as $100 \%$. [107] To facilitate the inclusion of this phenomenon into reservoir simulators, many multipliers are generated to correlate the apparent permeability to the absolute permeability in different flow regimes. 
Experimental studies on permeability enhancement effects in tight formations date back to the early 20th century. In 1941, based on gas flooding experiments, Klinkenberg [108] proposed a correlation equation of the apparent gas permeability $k a$ to the absolute permeability $k_{\infty}$ via

$$
k_{a}=\left(1+\frac{b}{p}\right) k_{\infty}
$$

where $b$ is the Klinkenberg factor and $p$ represents average pressure across the core. The Klinkenberg factor is usually obtained by matching experimental data. Klinkenberg's correction can be applied in the low Knudsen number range $(<0.1)$, therefore it is widely adopted for simulating low permeability gas reservoirs. The Klinkenberg factor is often calculated by a function of the absolute permeability and the rock porosity. Different expressions of Klinkenberg factor $b$ can be found in [109-111].

So far, no satisfactory apparent permeability correction has been developed for the transitional flow regime due to its complexity. A widely accepted correlation equation is proposed in 1999 by Beskok [112], with the multiplier relevant to $K n$, and many other correlations have been developed based on it,

$$
K=K_{\infty} f(K n)
$$

In the above equation, $f(K n)$ is a flow condition function given as a function of the Knudsen number $K n$, the dimensionless rarefaction coefficient $\alpha$, and the slip coefficient $b$, which is an empirical parameter, by:

$$
f(K n)=(1+\alpha K n)\left(1+\frac{4 K n}{1-b K n .}\right)
$$

The most important parameter is the slip coefficient, which is described as "the vorticity flux into the surface divided by the vorticity of flow field on the surface, obtained by the no-slip approximation". [63] To obtain the value, direct simulation Monte Carlo (DSMC) method or linearized Boltzmann equation are the two main approaches commonly used and sometimes laboratory experiments are designed for this. Slippage effects are enhanced at low pressure condition and the adsorption layer thickness is reduced, which results in a larger coefficient measured at ambient condition experiments. [113] The linearity property of Darcy's law is broken as the permeability increases. A new developed model of Beskok type scheme to calculate multiplier is proposed recently as [113]

$$
f\left(K_{n}\right)= \begin{cases}1+5 K_{n} & \text { Slip Regime } \\ 0.8453+5.4576 K_{n}+0.1633 K_{n}^{2} & \text { Transition Regime }\end{cases}
$$

Within the free molecular or Knudsen flow regime, the apparent gas permeability can be calculated by considering the diffusivity for Knudsen diffusion from gas kinetics.

$$
D=\frac{1}{3} d u=\frac{1}{3} d \sqrt{\frac{8 R T}{\pi M_{A}}}
$$


where $u$ is gas molecules thermal velocity, $R$ is the gas constant, and $M_{A}$ is the gas molecular weight. The derivation of Knudsen diffusion coefficient can be found in [114]. By rearranging the above equation, we can get an apparent gas permeability formulation similar to the Klinkenberg's correlation:

$$
k_{a}=\left(1+\frac{b}{p}\right) k_{\infty}
$$

where $b_{a}=p c_{g} \mu_{g} D / k_{\infty} \cdot[115]$

Slip flow, transition diffusion and surface diffusion are incorporated in a flux model proposed in 2017 [116], and the apparent permeability is derived as:

$$
k_{a p p}=\frac{F r^{2}}{8}+\frac{\mu D_{T}}{p}+\frac{\mu D_{s} \varsigma_{m s} R T C_{s}}{p^{2}}
$$

In table 5 , we listed different types of apparent permeability correction models that have been proposed. It is noted that Sun's model is a developed model based on classical Klinkenberg equation, which is proved with better accuracy. [115]

Table 5 Comparison of different apparent permeability correction models

\begin{tabular}{|c|c|c|c|}
\hline Model & Equation & Regime & Ref \\
\hline \hline Klinkenberg & $k_{a}=\left(1+\frac{b}{p}\right) k_{\infty}$ & Low Knudsen number & {$[108]$} \\
\hline Beskok & $f(K n)=(1+\alpha K n)\left(1+\frac{4 K n}{1-b K n .}\right)$ & Transitional flow & {$[112]$} \\
\hline Pour & $f\left(K_{n}\right)=\left\{\begin{array}{l}1+5 K_{n} \\
0.8453+5.4576 K_{n}+0.1633 K_{n}^{2}\end{array}\right.$ & Transitional flow & {$[113]$} \\
\hline Sun & $k_{a}=\left(1+\frac{b_{\alpha}}{p}\right) k_{\infty}$ & free molecular flow & {$[115]$} \\
\hline He & $k_{a p p}=\frac{F r^{2}}{8}+\frac{\mu D_{T}}{p}+\frac{\mu D_{s} S_{m s} R T C_{s}}{p^{2}}$ & free molecular flow & {$[116]$} \\
\hline
\end{tabular}

\subsection{Improved Darcy model in fractures}

It is important to modify original Darcy's equation to consider turbulent flow pattern of the gas transport in shale fractures where the inertial forces are relatively high. [117] Forchheimer equation is a common used formula to describe non-Darcy flow. It is observed that the linear relationship between the fluid velocity and pressure gradient in traditional Darcy's law is no longer valid at high flow rates. The non-Darcy flow coefficient, $\beta$, is then defined as a secondary proportional constant in addition to the permeability $k$ to introduce the nonlinearity. The improved model with the two coefficients can be written as

$$
-\frac{\mathrm{d} p}{\mathrm{~d} x}=\frac{\mu v}{k}+\beta \rho v^{2}
$$

Non-Darcy coefficient $\beta$ is of growing interest as it can be easily used in reservoir simulation. [118] Many theoretical correlations have been developed to calculate this parameter. A comprehensive model derived from experimental data is applied in numerical simulation, which is proved to be valid for single phase gas flow in porous media 
belonging to all ranges of flow regimes. [119] A parallel and serial two-type model is proposed to describe the porous structure. [120] In this classification, the porous medium is assumed to be made up of straight bundle and parallel capillaries with uniform diameter in parallel type. The serial type is assuemd to the structure serially lined pore space. For both the two models, non-Darcy coefficient $\beta$ is given as

$$
\beta=\frac{c}{K^{0.5} \phi^{1.5}} \text { Parallel type model }
$$

It is found that the above equation with additional quadratic term of velocity is limited within certain range of data set. [121] To handle deviations, another cubic term of velocity is introduced to better meet all data set:

$$
-\frac{\partial p}{\partial x}=\frac{\mu v}{k}+\beta \rho v^{2}+\gamma \rho v^{3}
$$

However, the above Forchheimer cubic equation with constant $\beta$ and $\gamma$ parameters still not meet all the data set very well. Apparent permeability is observed to be larger than predictions using Forchheimer type equations at high flow rate. Based on extensive laboratory and field experimental data sets, a new and more general model, which is knwon as Barree and Conway model [12], is proposed in 2004 to overcome the problems caused by constant $\beta$ and $\gamma$ values. Darcy's now is again valid in the Barree and Conway model, with apparent permeability:

$$
-\frac{\partial p}{\partial L}=\frac{\mu v}{k_{a p p}}
$$

Barree and Conway model is proved to address the discrepancies, which may cause significant impact on the relationship between pressure and flow rate distribtuion in porous media. [122] As shown in Fig. 3, the Barree and Conway model meets much better with the experimental data of pressure drop and flow rate, while Forchheimer quadratic equation will overestimate the pressure drop at high flow rate but Forchheimer cubic equation underestimate the pressure drop.

The Barree and Conway model (BCM) has widely applied in modern petroleum industry as a basic mathematical model of shale gas reservoir simulator. A 3D single phase fluid flow scheme is derived according to Forchheimer and BCM equations to simulate pressure transient analysis in fractured reservoirs. [123] Combining both the two equations, an equivalent non-Darcy flow coefficient can be calculated to describe all non-Darcy flow phenomenons coupling with near-wellbore effects. Besides, the BCM has already been extended to model the multiphase flow in porous media, which is widely used in practical shale gas reservoir simulator. [124]

The recent development of shale gas reservoir simulation technics has witnessed new evolutions based on Barree and Conway model. Barree [125] improved this model with no more assumptions of a constant permeability or a constant $\beta$. In the new model, correlations of pressure drop and flow velocity can be valid for the whole porous media [126]: 


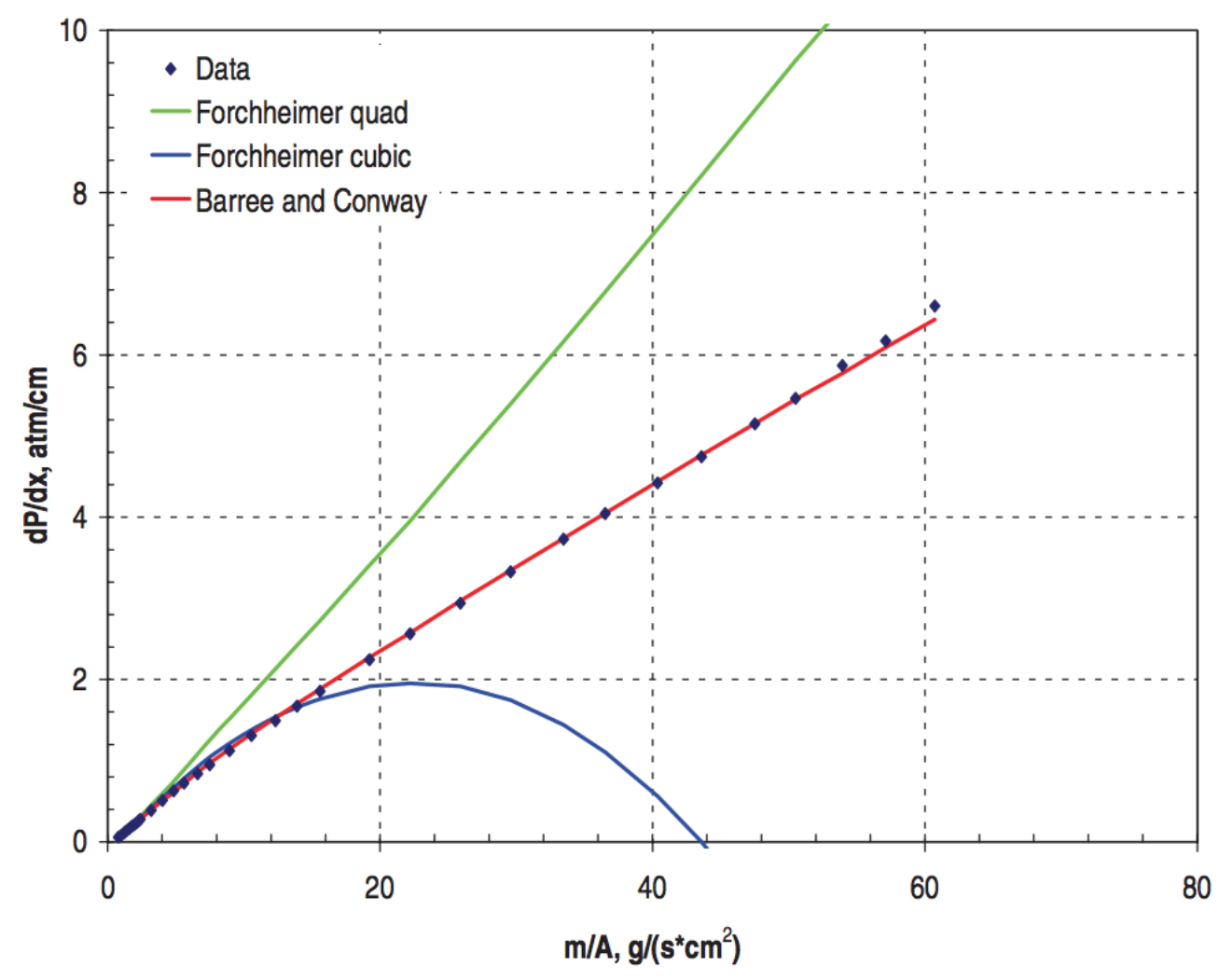

Fig. 3 The comparison between pressure gradient and mass flow rate under certain condition with different models[122]

$$
\frac{\partial p}{\partial L}=\mu v / k_{\mathrm{d}}\left[k_{\mathrm{mr}}+\frac{\left(1+k_{\mathrm{mr}}\right)}{\left(1+\frac{\rho v}{\mu T}\right)}\right]
$$

\section{Gas flow simulation at reservoir scale}

\subsection{Flow models}

Shale is generally viewed as sediments with very fine grains and obvious fissility. [127]. The porous media, constituting of pores with diameters ranging from nanometer to micrometer, is classified into inter-particle and intra-particle pores. The intra-particle pores are associated with organic matter pores within kerogen and mineral particles [128].

Different physical properties has been illustrated in the organic matter pore compared with rock constituents common seen. The special properties play significantly impact on the gas storage and flow in shale. Numerous small pores are found in larger pores residing on their interior walls in kerogen. [129] Besides, cross section of pores in kerogen are observed to be round. Kerogen is also thought to be the place where gas adsorb on the wall and dissolve within it. $[127,130]$ The pore structure in organic matter is generally considered as gas-wetting due to it is formed in hydrocarbon gen- 
eration process. $[131,132]$ As the organic matter is so unique with these features, a four type classification of organic-rich shale structure is common accepted, where the porosity systems are divided into hydraulic fracture, natural fractures, kerogen (organic matrix) and inorganic matter the pore size decreasing [132], as shown in Fig. 4. Another classification approach is to categorize the shale reservoir into four different pore systems as organic porosity, inorganic porosity, natural fractures, and hydraulic fractures. [133]

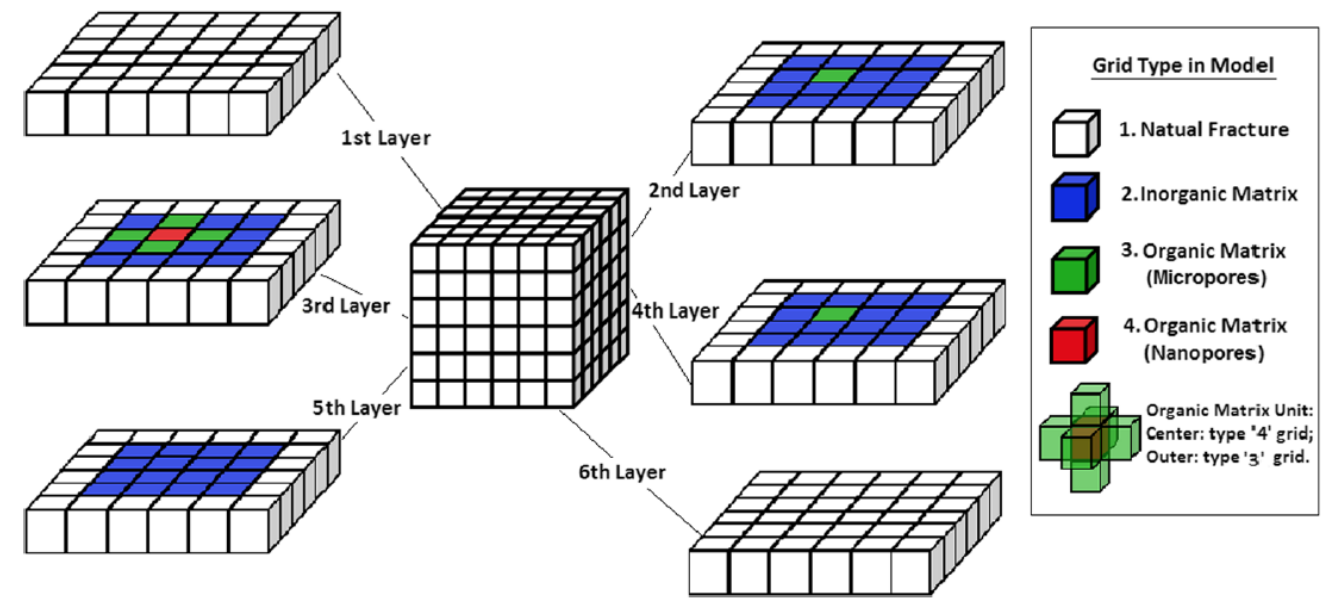

Fig. 4 Schematic of micro-scale model: a grid system for instance, with one organic matrix unit randomly distributed in shale matrix core surrounded by natural fracture $\operatorname{grid}[134]$

Different approaches have been developed to capture the shale properties in reservoir simulations. Multiple interacting continua (MINC) and explicit fracture modeling are proposed to generate an efficient scheme with single porosity for shale gas simulation. [135] A coarse-grid model incorporating numerical dynamic skin factor is presented for shale reservoirs with hydraulic fractures. [136] To handle practical well performance in a long term as well as common transient behavior, the coarse-grid model is improved to better describe the fractures and wells. [137]

For different connections in organic matters with different pore sizes, free gas flow mechanism varies. Generally speaking, for connections between nano-pores and micropores in organic matter, only Fickian diffusion is the driven of desorbed gas flow. For connections between micro-pores in organic matters, both Darcy's law and Fickian diffusion should be considered. For other connections, Darcy's law is often assumed to be the only driven force. A general mass conservation equation is derived to accommodate all the three assumptions and describe a single-component and single-phase isothermal flow system [134]:

$$
\nabla \cdot\left[\rho_{g}\left(D_{f} C_{g} \nabla P+\frac{K}{\mu_{g}}\left(\nabla p+\rho_{g} g \nabla z\right)\right)\right]=-\left[\frac{\partial\left(\rho_{g} \varphi\right)}{\partial t}+\frac{\partial\left(q_{a}(1-\varphi)\right)}{\partial t}\right]
$$

where $D_{f}$ is the Fickian diffusion coefficient, $C_{g}$ is the gas permeability, $\mu_{g}$ is the gas viscosity, $K$ is the media permeability, $q_{a}$ is the mass of gas adsorbed on unit volume of 
media and $\varphi$ is the porosity of the porous media. The first term on the left hand side of above equation represents the Fickian diffusion flux, the second term represents the Darcy flow flux. On the right hand side, the first term refers to the compressed gas in all the grids and the second term refers to the accumulation of desorbed gas in organic grid blocks.

Darcy's law is quite limited in shale matrix as the permeability is extremely low there. As a result, many innovative methods have been proposed to investigate the flow mechanisms instead of dual-permeability and dual porosity models common used in conventional oil and gas reservoirs. One approach is called the dual-mechanism model, which considers both the Fickian diffusion and Darcy flow, and dynamic gas slippage factor is introduced to describe the gas flow in tight formations. [138, 139] Another method is proposed in 2012 [140], using a flow condition function of Knudsen number to correct apparent permeability with intrinsic permeability. However, further confirmation is still needed to validate the suitability to various flow regimes. An improved multiple-porosity model is recently developed [134], where several porosity systems are tied through arbitrary connectivities against each other, as shown in Fig. 5. It is illustrated that upscaling techniques can be used to extend this model to shale gas flow simulation at reservoir scale with complex mechanisms.

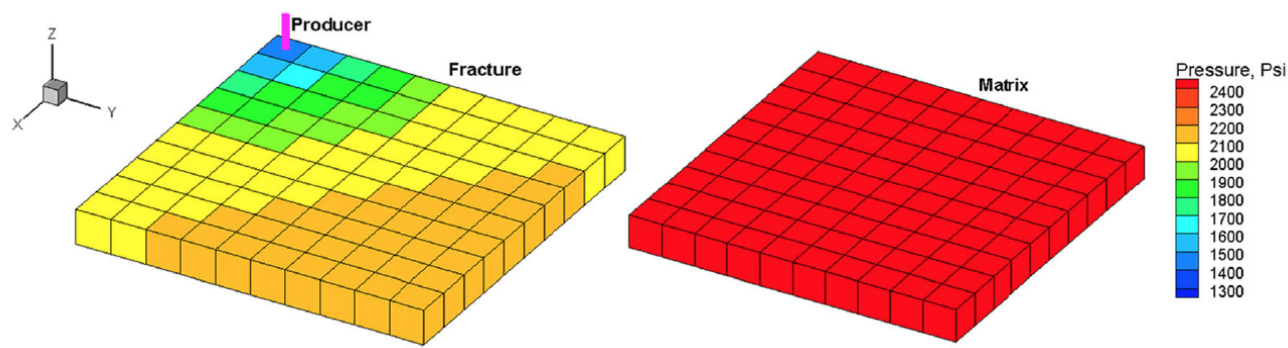

Fig. 5 Dual-porosity model used for validation of variable permeability, left map: fracture; right map: matrix[134]

\subsection{Flow model coupled with geomechanics}

Geomechanics is of critical importance to be incorporated in the reservoir simulation to better describe the underground pressure and velocity distribution. An efficient and reliable prediction on hydrocarbon production is closely relevant to an accurate description of rock physics which might be changed by field operations.

Due to the complex rock characteristics in shale gas reservoirs, geological conditions are hard to depict and model with conventional methods. [141] After a quick review on previous studies coupling geomechanics and flow models in shale gas reservoirs, two classifications are concluded with different focus. Some researches are concentrated on the improvement of model accuracy, efficiency and reliability. [142-146] Iterative methods are developed [142], space discretization is optimized [143] and solution convergence is improved. [144] Meanwhile, practical applications of coupled models on shale gas 
reservoir exploration processes are discussed. $[147,148]$ Effects of plasticity on production performance is taken into account [147] and the difference of introducing responses to field operations is demonstrated. [148] A well-established flow model coupled with geomechanics is proposed recently to examine the effects of hydraulic fracture geometry and rock mechanics on hydrocarbon production and pressure distribution in unconventional reservoirs. The fully coupled numerical model is validated with an analytical solution and used to history match with field data. This model has been proved to be successful in the investigation of reservoir performance and in the characterization of the pressure distribution in cases with various rock elastic properties and hydraulic fracture designs. [149]:

$$
\begin{gathered}
\rho_{g}\left[\frac{\alpha-\phi}{K_{s}}+\phi \frac{M_{g}}{R T \rho_{g}}\left(\frac{1}{z_{g}}-\frac{p}{z_{g}^{2}} \frac{\partial z_{g}}{\partial p_{g}}\right)\right] \frac{\partial p_{g}}{\partial t}+\rho_{g} \alpha \frac{\partial e_{v}}{\partial t}+\nabla \cdot\left(\rho_{g} v\right)=\rho_{g} q_{g} \\
\nabla \cdot\left[\sigma_{0}+\lambda \operatorname{tr}(\varepsilon) I+2 \mu \varepsilon-\alpha\left(p-p_{0}\right) I\right]=0
\end{gathered}
$$

where $z_{g}$ is the real gas factor, $M_{g}$ is the gas molar mass, $R$ is the gas constant, $T$ is the absolute temperature, $\alpha$ is the Biot's coefficient, $\sigma_{0}$ is the initial total stress tensor, $\lambda$ is the first Lame's constant, $\mu$ is the second Lame's constant and $\operatorname{tr}(\varepsilon)$ is the trace of strain tensor.

Necessary properties needed for production workflow, like pressure and deformation process, can be better provided from the coupling models. [150] It is found in previous research [151] that gas production will be overestimated if geomechanics is not incorporated in the flow models. The production rate in naturally fractured reservoirs is proved to be highly sensitive to fracture aperture changes. [152] With the introducing of stress sensitivity, well production will be reduced. The effect of total organic carbon (TOC) on gas production is studied with a model coupling geomechanics and flow, and the cumulative production is said to be increased if TOC is larger. [153]

Generally, only linear elasticity is considered in geomechanics numerical model, which leads to the disability of recovering nonlinear elastic behaviors caused by hydrocarbon depletion and srress changes in shale gas reservoirs. [153, 154] To handle this problem, an enhanced coupling model is proposed recently to consider nonlinear elasticity. [155] It is found that as rocks are being compacted and consolidated during the production process, permeability values are quite different and meet experiment data better than linear elasticity models on samples obtained from the Longmaxi Formation in China. It is indicated that permeability will be overestimated by 1.6 to 53 time if nonlinear elasticity is not considered.

\section{Macroscopic numerical simulation approaches}

Analytical methods are not capable of solving the mathematical formulas constituting flow models of shale gas reservoirs. As a result, numerical methods are strongly needed to solve the model. In petroleum industry, numerical simulations can go back to 1950s, 
and now have been applied in a wide range of complex fluid flow processes. Except for microscopic and mesoscopic approaches discussed in Section 2, macroscopic approaches are also common methods to provide numerical solutions of fluid flow in shale gas reservoirs. Due to the long history of the application, some macroscopic approaches, like finite difference method (FDM) and finite element method (FEM) are more common used and well developed. Recently, efforts have also been paid on other methods including finite volume method (FVM) and fast matching method(FMM).

\subsection{Finite Difference Method}

In reservoir simulation, and even larger scale of flow simulation, FDM is always viewed as the most commonly used and best developed method. Discretization of ordinary and partial differential equations modeling flow in reservoirs are the first procedure in the technique. Afterwards, a finite difference grid should be constructed on the simulated reservoir area and the method implementation is conducted on the grids. For boundary conditions, pressure information is common used at each boundary point at the block. [156] It is found that the accuracy of numerical results using finite difference methods is deeply relevant to the grid division and boundary conditions. [157] Truncations on Taylor series expansion are used to solve unknown velocity and pressure distribution with spatial derivatives. [158]

The main advantage of FDM over FEM is the efficiency and simplicity. Rectangular and triangular grids, uniform and non-uniform meshes, Cartesian and curvilinear coordinates have all been proved to be easy to implement in reservoir simulations extended from 1D to 3D. Especially for 3D complex flow problems, FDM is said to be far superior, although problems like numerical dispersion and grid dependence may occur.[159]

\subsection{Finite Element Method}

Compared to FDM, FEM is said to be more accurate in reservoir simulations. Opposed to piecewise constant approximation, FDM results in a linear approximation solution. [160] Besides, the flexibility of accommodations to unstructured meshes is demonstrated in studies using FEM. As a result, FEM is more capable of describing flow properties in complex porous structures in reservoir geometry from fracture to matrix, and excellent efficiency could still be preserved. [160, 161]

Complex rock structures in special geometry of shale gas formations, such as nonplanar and non-orthogonal fractures, make Cartesian grids inadequate to be used in shale gas reservoir simulation using FEM. Thus, unstructured meshing is required to capture the fracture geometry. [162] Starting from 1979 [163], unstructured meshing skills have been widely used and extended to incorporations with local grid refinement. [157, 164] A new compositional model based on unstructured PEBI (perpendicular bisector) is proposed in 2015 [165] to characterize the properties of non-Darcy flow in a wide range of slip, transitional and free molecular flow regimes and multi-component adsorption 
processes. Although much time and effort should be paid on the grids generation, the advantages of unstructured meshing skills are still worthwhile. Complex boundary conditions such as pinch out and faults can be represented much more easily and local refinement is more flexible. To orient grids when needed, it is easier as well compared to structured grids. The improvement of accuracy by unstructured grids is proved in previous studies [166], as well as CPU performance. An example of two kinds of unstructured is illustrated in Fig. 6.

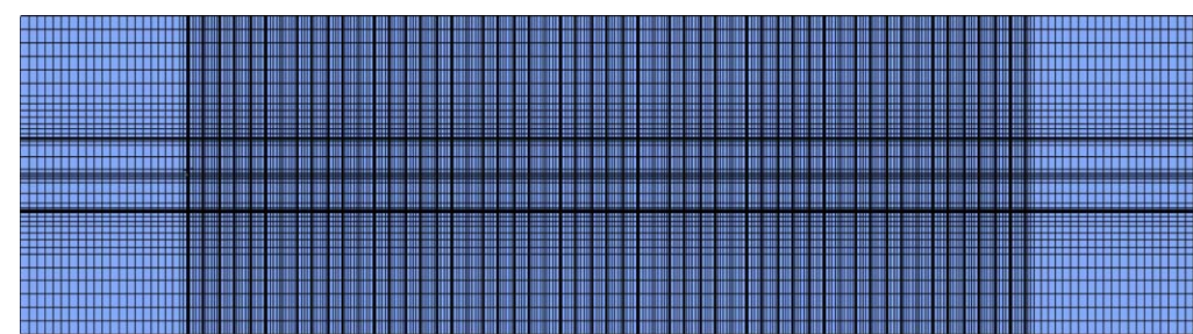

(a)

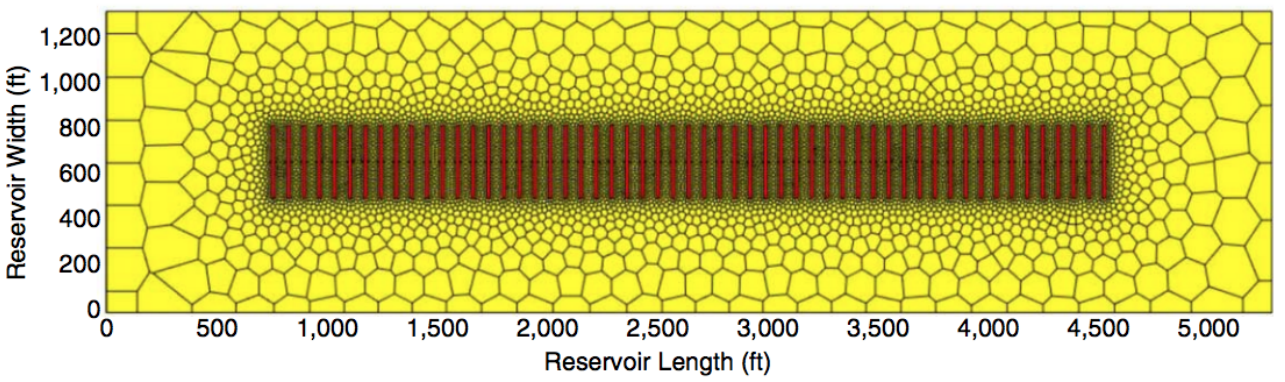

(b)

Fig. 6 The comparison between (a) the tartan grid and (b) the PEBI grid for 2D synthetic model[166]

Upscaling or homogenization techniques are widely used in traditional researches to develop effective parameters that represent subscale behavior in an averaged sense on a coarser scale as flow modeling needs to be concerned on a wide range of spatial and temporal scales in practical reservoir simulation. [167-170] In an attempt to overcome some of the limitations of upscaling methods, so-called multiscale discretization methods have been proposed over the past two decades to solve second-order elliptic equations with strongly heterogeneous coefficients[171]. This includes methods such as the generalized finite-element methods [172], numerical-subgrid upscaling [173], multiscale mixed finiteelement methods [174] and mortar mixed finite-element methods. [175] The key idea of all these methods is to construct a set of prolongation operators (or basis functions) that map between unknowns associated with cells of the fine geo-cellular grid and unknowns on a coarser grid used for dynamic simulation. Over the past decade, there have primarily been main developments in this direction focusing on the multiscale mixed finite-element (MsMFE) method. The main process is to make this method as geometrically flexible as possible and developing coarsening strategies that semi-automatically adapt to barriers, channels, faults, and wells in a way that ensures good accuracy for a chosen level of coarsening. In order to produce high-quality approximate solutions for 
complex industry-standard grids with high aspect ratios and unstructured connections, a new multiscale formulation has been presented recently [176], which could guarantee the robustness, accuracy, flexibility as well as simplification on the implementation. Besides, many works have been done on the weighted Jacobi smoothing on interpolation operators with a large degree of success in the algebraic multigrid (AMG) community where fast coarsening is combined with simple operators constructed via one or two smoothing steps [177-179] as an inexpensive alternative to the interpolation operators used in standard AMG [180]. Many high performance multigrid solvers have been proposed to support smoothed aggregation as a strategy for large, complex problems [181] due to the inexpensive coarsening and interpolation strategies.

\subsection{Other Methods}

For reservoir simulations incorporating complex rock geometries, finite volume method (FVM) is said to be more easily implemented with unstructured grids. It is a fairly new developed technique and mainly focusing on discretization methodologies. [182] It is proved that to get numerical approximations at the same level of accuracy, FVM is easier and faster compared to FEM. Compared to FDM, FVM is believed to have better versatility.

Another comprehensive approach in shale gas reservoir simulation is a class of fronttracking methods called fast marching method (FMM). [183-186] The well-drainage volume can be computed efficiently using this method, where the propagation equation (Eikonal equation [187] is directly solved of a maximum impulse response. [188] FMM is proved to be very efficient in solving the Eikonal equation, where CPU times are only in seconds level but other comparable methods need hours. Besides the close corresponding with the analytic solution, the common front resolution problems are also solved. [189] Fig. 7 shows two illustrative examples using FMM method with unstructured triangular grids.

\section{Conclusion}

This paper reviews the flow mechanism and numerical simulation approaches of shale gas reservoirs. Investigation of gas adsorption/desorption is important to predict well production, and gas adsorption isotherm can be concluded into different models. With the classification of flow regimes based on Knudsen number, different governing equations and numerical approaches are suitable for different gas transport mechanism. Microscopic and mesoscopic approaches, represented by Molecular Dynamics (MD) and Lattice Boltzmann Method (LBM), have successfully been applied in the study of shale gas mechanisms, in particular interests of studying Klinkenberg effect, Knudsen diffusion, molecular velocity and many other details of special mechanisms of shale gas flow in reservoirs. Due to the special mechanisms and percolation characteristics of shale gas transport, classical Darcy's law should be corrected and the concept of apparent 


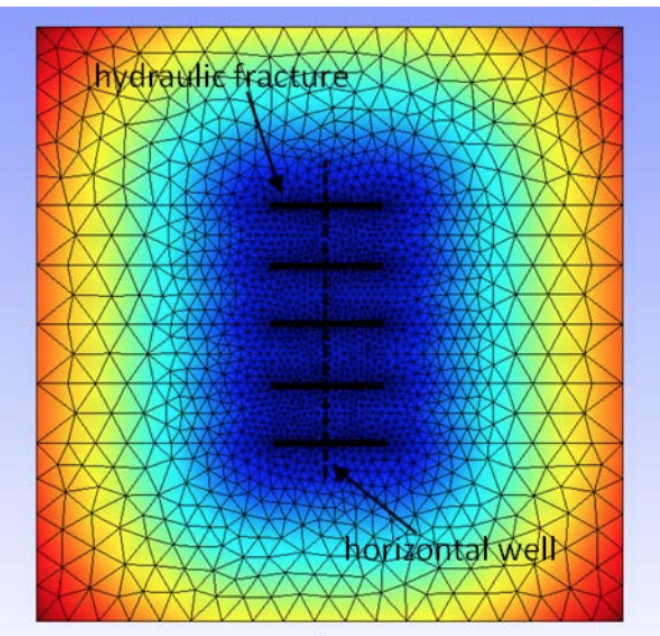

(a)

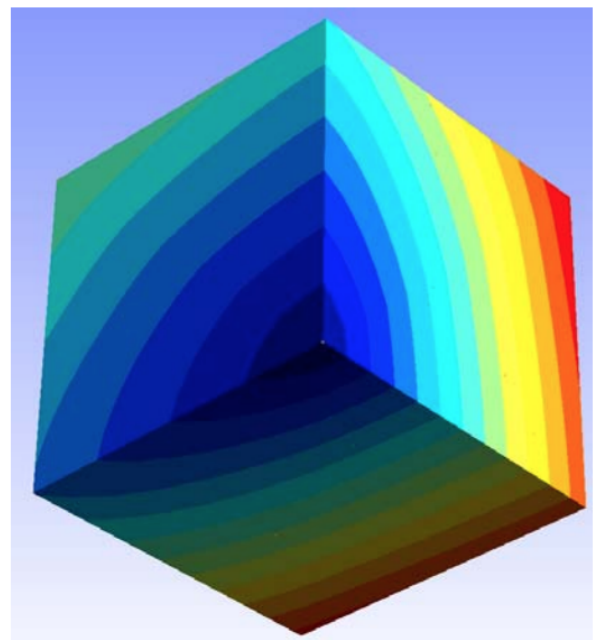

(b)

Fig. 7 Fast matching approach simulation examples using unstructured grids (a) 2D examples with isotropic permeability (b) 3D example with anisotropic permeability [186]

permeability is introduced. For flow at high rate, e.g. in fractures, improved Darcy's model with high-order terms of velocity are presented to better describe the gas flow.

In reservoir scale flow models, shale is usually classified into four types: inorganic matter, organic matrix (kerogen), natural fractures, and hydraulic fractures. Various models of gas transport in shale with detailed description on fracture characterizations have been developed, including single-porosity, dual porosity and many others. Besides, it is critical to incorporate general reservoir flow model with geomechanics in order to better understand the pressure and reservoir performance in hydrocarbon development. Due to the long history and better visibility, the petroleum industry is more familiar with macroscopic numerical approaches, including the finite difference method (FDM) and finite element method (FEM). Recent progress have also been made on other methods, like finite volume method (FVM) and fast matching method(FMM).

\section{Acknowledgements}

The research reported in this publication was supported in part by funding from King Abdullah University of Science and Technology (KAUST) through the grant BAS/1/135101-01. The authors are also grateful for financial support from the Beijing Nova Program under Grant No. Z171100001117081 and the Fundamental Research Funds for the Central Universities under Grant No. FRF-TP-17-001C1.

\section{References}

[1] M.-T. Le, "An assessment of the potential for the development of the shale gas industry in countries outside of north amer- 
ica," Heliyon, vol. 4, no. 2, p. e00516, 2018. [Online]. Available: http://www.sciencedirect.com/science/article/pii/S2405844017312549

[2] Q. Wang, X. Chen, A. N. Jha, and H. Rogers, "Natural gas from shale formationthe evolution, evidences and challenges of shale gas revolution in united states," Renewable and Sustainable Energy Reviews, vol. 30, pp. 1-28

[3] W. E. Hefley and Y... Wang, Economics of Unconventional Shale Gas Development. Springer, 2016.

[4] T. Zhang, A. Salama, S. Sun, and M. F. El-Amin, "Pore network modeling of drainage process in patterned porous media: A quasi-static study," Journal of Computational Science, vol. 9, pp. 64-69, 2015. [Online]. Available: http://www.sciencedirect.com/science/article/pii/S1877750315000484

[5] W. E. Hefley and Y... Wang, Economics of Unconventional Shale Gas Development. Springer, 2016.

[6] T. . Bros, After the US shale gas revolution. Editions Technip, 2012.

[7] Y. Wang and W. E. Hefley, The Global Impact of Unconventional Shale Gas Development: Economics, Policy, and Interdependence. Springer, 2016, vol. 39

[8] C. L. Cipolla, E. P. Lolon, J. C. Erdle, and B. Rubin, "Reservoir modeling in shale-gas reservoirs," 2010.

[9] B. Rubin, "Accurate simulation of non darcy flow in stimulated fractured shale reservoirs," 2010.

[10] X. Wang and T. Wang, The shale gas potential of China. Society of Petroleum Engineers, 2011.

[11] N. C. Reis Jr, J. P. De Angeli, A. F. de Souza, and R. H. Lopes, "Petroleum reservoir simulation using finite volume method with non-structured grids and parallel distributed computing," 2001.

[12] R. D. Barree and M. W. Conway, "Beyond beta factors: A complete model for darcy, forchheimer, and trans-forchheimer flow in porous media," 2004.

[13] T. Babadagli, S. Raza, X. Ren, and K. Develi, "Effect of surface roughness and lithology on the water-gas and water-oil relative permeability ratios of oil-wet single fractures," International Journal of Multiphase Flow, vol. 75, pp. 68-81, 2015. [Online]. Available: http://www.sciencedirect.com/science/article/pii/S0301932215001226

[14] R. M. Pollastro, "Total petroleum system assessment of undiscovered resources in the giant barnett shale continuous (unconventional) gas accumulation, fort 
worth basin, texas," vol. 91, no. 4, pp. 551-578, 2007. [Online]. Available: http://pubs.er.usgs.gov/publication/70029918

[15] X.-C. Lu, F.-C. Li, and A. T. Watson, "Adsorption measurements in devonian shales," Fuel, vol. 74, no. 4, pp. 599-603

[16] Z. Huan-zhi and H. Yan-qing, Resource Potential and Development Status of Global Shale Gas [J], 2010, vol. 6.

[17] D. J. K. Ross and R. Marc Bustin, Shale gas potential of the Lower Jurassic Gordondale Member, Northeastern British Columbia, Canada, 03 2007, vol. 55.

[18] J. B. Curtis, "Fractured shale-gas systems," AAPG bulletin, vol. 86, no. 11, pp. 1921-1938

[19] W. V. Grieser, R. F. Shelley, and M. Y. Soliman, Predicting production outcome from multi-stage, horizontal Barnett completions. Society of Petroleum Engineers, 2009.

[20] T. Zhang, G. S. Ellis, S. C. Ruppel, K. Milliken, and R. Yang, "Effect of organicmatter type and thermal maturity on methane adsorption in shale-gas systems," Organic geochemistry, vol. 47, pp. 120-131 2012.

[21] X. Wei, G. Wei, L. Honglin, G. Shusheng, H. Zhiming, and Y. Farong, "Shale reservoir characteristics and isothermal adsorption properties," Natural Gas Industry, vol. 32, no. 1, pp. 113-116, 2012.

[22] Z. Zhang and S. Yang, "On the adsorption and desorption trend of shale gas," Journal of Experimental Mechanics, vol. 27, no. 5, pp. 492-497, 2012.

[23] J. Tan, P. Weniger, B. Krooss, A. Merkel, B. Horsfield, J. Zhang, C. J. Boreham, G. v. Graas, and B. A. Tocher, "Shale gas potential of the major marine shale formations in the upper yangtze platform, south china, part ii: Methane sorption capacity," Fuel, vol. 129, pp. 204-218, 2014. [Online]. Available: http://www.sciencedirect.com/science/article/pii/S0016236114003159

[24] M. G. Bjørner, A. A. Shapiro, and G. M. Kontogeorgis, "Potential theory of adsorption for associating mixtures: possibilities and limitations," Industrial Engineering Chemistry Research, vol. 52, no. 7, pp. 2672-2684

[25] T. F. Rexer, M. J. Benham, A. C. Aplin, and K. M. Thomas, "Methane adsorption on shale under simulated geological temperature and pressure conditions," Energy Fuels, vol. 27, no. 6, pp. 3099-3109

[26] X. Guo, J. Kim, and J. E. Killough, "Hybrid mpi-openmp scalable parallelization for coupled non-isothermal fluid-heat flow and elastoplastic geomechanics," 2017. 
[27] C. Guo, M. Wei, H. Chen, X. He, and B. Bai, Improved numerical simulation for shale gas reservoirs. Offshore Technology Conference, 2014.

[28] H. R. O., "Kapillarchemie, eine darstellung der chemie der kolloide und verwandter gebiete. von dr. herbert freundlich. verlag der akademischen verlagsgesellschaft. leipzig 1909. 591 seiten. preis 16,30 mk., geb. 17,50 mk," Zeitschrift für Elektrochemie und angewandte physikalische Chemie, vol. 15, no. 23, pp. 948-948, 2018/04/01 2010. [Online]. Available: https://doi.org/10.1002/bbpc.19090152312

[29] I. Langmuir, "The adsorption of gases on plane surfaces of glass, mica and platinum." Journal of the American Chemical Society, vol. 40, no. 9, pp. 1361-1403, 09 1918. [Online]. Available: https://doi.org/10.1021/ja02242a004

[30] S. Brunauer, P. H. Emmett, and E. Teller, "Adsorption of gases in multimolecular layers," Journal of the American chemical society, vol. 60, no. 2, pp. 309-319

[31] M. Dubinin, "The potential theory of adsorption of gases and vapors for adsorbents with energetically nonuniform surfaces." Chemical Reviews, vol. 60, no. 2, pp. 235241

[32] — - "Modern state of the theory of gas and vapour adsorption by microporous adsorbents," Pure and Applied Chemistry, vol. 10, no. 4, pp. 309-322

[33] F. Yang, Z. Ning, and H. Liu, "Fractal characteristics of shales from a shale gas reservoir in the sichuan basin, china," Fuel, vol. 115, pp. 378-384, 2014. [Online]. Available: http://www.sciencedirect.com/science/article/pii/S001623611300639X

[34] X. Su, R. Chen, X. Lin, and Y. Song, "Application of adsorption potential theory in the fractionation of coalbed gas during the process of adsorption/desorption," Acta Geologica Sinica, vol. 82, no. 10, pp. 1382-1389, 2008.

[35] J.-S. Bae and S. K. Bhatia, "High-pressure adsorption of methane and carbon dioxide on coal," Energy Fuels, vol. 20, no. 6, pp. 2599-2607 0887-0624, 2006.

[36] A. Dada, A. Olalekan, A. Olatunya, and O. Dada, "Langmuir, freundlich, temkin and dubinin-radushkevich isotherms studies of equilibrium sorption of zn2+ unto phosphoric acid modified rice husk," IOSR Journal of Applied Chemistry, vol. 3, no. 1, pp. 38-45, 2012.

[37] T. Zhang, G. S. Ellis, S. C. Ruppel, K. Milliken, and R. Yang, "Effect of organic-matter type and thermal maturity on methane adsorption in shale-gas systems," Organic Geochemistry, vol. 47, pp. 120-131, 2012. [Online]. Available: http://www.sciencedirect.com/science/article/pii/S0146638012000629

[38] M. A. Ahmadi and S. R. Shadizadeh, "Experimental investigation of a natural surfactant adsorption on shale-sandstone reservoir rocks: Static and 
dynamic conditions," Fuel, vol. 159, pp. 15-26, 2015. [Online]. Available: http://www.sciencedirect.com/science/article/pii/S0016236115006158

[39] L. Ming, G. Anzhong, L. Xuesheng, and W. Rongshun, "Determination of the adsorbate density from supercritical gas adsorption equilibrium data," Carbon, vol. 3 , no. 41 , pp. $585-588$

[40] S. Chen, Y. Zhu, H. Wang, H. Liu, W. Wei, and J. Fang, "Shale gas reservoir characterisation: A typical case in the southern sichuan basin of china," Energy, vol. 36, no. 11, pp. 6609-6616, 2011. [Online]. Available: http://www.sciencedirect.com/science/article/pii/S0360544211005986

[41] X. Luo, S. Wang, Z. Wang, Z. Jing, M. Lv, Z. Zhai, and T. Han, "Adsorption of methane, carbon dioxide and their binary mixtures on jurassic shale from the qaidam basin in china," International Journal of Coal Geology, vol. 150, pp. 210223

[42] W. Yu, K. Sepehrnoori, and T. W. Patzek, "Modeling gas adsorption in marcellus shale with langmuir and bet isotherms," 2016.

[43] T. F. T. Rexer, M. J. Benham, A. C. Aplin, and K. M. Thomas, "Methane adsorption on shale under simulated geological temperature and pressure conditions," Energy $\&$ Fuels, vol. 27, no. 6, pp. 3099-3109, 06 2013. [Online]. Available: https://doi.org/10.1021/ef400381v

[44] X. Tang, N. Ripepi, N. P. Stadie, L. Yu, and M. R. Hall, "A dual-site langmuir equation for accurate estimation of high pressure deep shale gas resources," Fuel, vol. 185, pp. 10-17, 2016. [Online]. Available: http://www.sciencedirect.com/science/article/pii/S0016236116306913

[45] F. O. Mertens, "Determination of absolute adsorption in highly ordered porous media," Surface Science, vol. 603, no. 10-12, pp. 1979-1984 0039-6028, 2009.

[46] X. Tang and N. Ripepi, "High pressure supercritical carbon dioxide adsorption in coal: Adsorption model and thermodynamic characteristics," Journal of CO2 Utilization, vol. 18, pp. 189-197

[47] N. P. Stadie, M. Murialdo, C. C. Ahn, and B. Fultz, "Unusual entropy of adsorbed methane on zeolite-templated carbon," The Journal of Physical Chemistry C, vol. 119, no. 47, pp. 26 409-26421

[48] J. Saulsberry, P. Schafer, R. Schraufnagel, and G. R. I. (U.S.), A Guide to Coalbed Methane Reservoir Engineering. Gas Research Institute, 1996. [Online]. Available: https://books.google.com.sa/books?id=D4UuuAAACAAJ 
[49] G. H. Z. X. C. L. L. D. L. J. Shen, Y., "Impact of fracturing liquid absorption on the production and water-block unlocking for shale gas reservoir," Advances in Geo-Energy Research, vol. 2, no. 2, pp. 163-172, 2018.

[50] Y. Zhou and L. Zhou, "Fundamentals of high pressure adsorption," Langmuir, vol. 25, no. 23, pp. $13461-13466$

[51] M. Dubinin, "The potential theory of adsorption of gases and vapors for adsorbents with energetically nonuniform surfaces." Chemical Reviews, vol. 60, no. 2, pp. 235241

[52] R. J. Ambrose, R. C. Hartman, and I. Y. Akkutlu, "Multi-component sorbed phase considerations for shale gas-in-place calculations," p. 10, 2011. [Online]. Available: https://doi.org/10.2118/141416-MS

[53] R. C. Hartman, R. J. Ambrose, I. Y. Akkutlu, and C. R. Clarkson, "Shale gas-in-place calculations part ii - multicomponent gas adsorption effects," p. 17, 2011. [Online]. Available: https://doi.org/10.2118/144097-MS

[54] E. Fathi and I. Y. Akkutlu, "Multi-component gas transport and adsorption effects during co2 injection and enhanced shale gas recovery," International Journal of Coal Geology, vol. 123, pp. 52-61, 2014. [Online]. Available: http://www.sciencedirect.com/science/article/pii/S0166516213001808

[55] J. Jiang, Y. Shao, and R. M. Younis, "Development of a multi-continuum multicomponent model for enhanced gas recovery and co2 storage in fractured shale gas reservoirs," p. 17, 2014. [Online]. Available: https://doi.org/10.2118/169114-MS

[56] K. M. Gerke, M. V. Karsanina, and D. Mallants, "Universal stochastic multiscale image fusion: an example application for shale rock," Scientific reports, vol. 5, pp. 15880

[57] J. Di and J. Jensen, "A closer look at pore throat size estimators for tight gas formations," Journal of Natural Gas Science and Engineering, vol. 27, pp. 12521260

[58] W. D. . McCain, The properties of petroleum fluids. PennWell Books, 1990.

[59] J. Kärger, "Flow and transport in porous media and fractured rock," Zeitschrift für Physikalische Chemie, vol. 194, no. 1, pp. 135-136

[60] J. Zhao, L. Yang, K. Xue, W. Lam, Y. Li, and Y. Song, "In situ observation of gas hydrates growth hosted in porous media," Chemical Physics Letters, vol. 612, pp. $124-128$

[61] W. He, J. Zou, B. Wang, S. Vilayurganapathy, M. Zhou, X. Lin, K. H. Zhang, J. Lin, P. Xu, and J. H. Dickerson, "Gas transport in porous electrodes of solid 
oxide fuel cells: a review on diffusion and diffusivity measurement," Journal of Power Sources, vol. 237, pp. 64-73

[62] B. Berkowitz and R. P. Ewing, "Percolation theory and network modeling applications in soil physics," Surveys in Geophysics, vol. 19, no. 1, pp. 23-72

[63] A. Beskok, G. E. Karniadakis, and W. Trimmer, "Rarefaction and compressibility effects in gas microflows," Journal of Fluids Engineering, vol. 118, no. 3, pp. 448-456, 09 1996. [Online]. Available: http://dx.doi.org/10.1115/1.2817779

[64] E. Ozkan, R. S. Raghavan, and O. G. Apaydin, "Modeling of fluid transfer from shale matrix to fracture network," 2010.

[65] H. ZHAO, M. CHEN, Y. JIN, Y. DING, and Y. WANG, "Rock fracture kinetics of the facture mesh system in shale gas reservoirs," Petroleum Exploration and Development, vol. 39, no. 4, pp. 498-503, 2012. [Online]. Available: http://www.sciencedirect.com/science/article/pii/S1876380412600676

[66] H. Song, Y. Wang, J. Wang, and Z. Li, "Unifying diffusion and seepage for nonlinear gas transport in multiscale porous media," Chemical Physics Letters, vol. 661, pp. 246-250, 2016. [Online]. Available: http://www.sciencedirect.com/science/article/pii/S0009261416304687

[67] C. Tian, Y. Chao, Y. Ying, D. Yan-Hong, G. Shui-Bin, X. Yi-Jun, N. Zhao-Yuan, P. Xiao-Ping, and W. Zhen-Ming, "Photoluminescence of silicone oil treated by fluorocarbon plasma," Chinese Physics B, vol. 21, no. 9, p. 097802, 2012. [Online]. Available: http://stacks.iop.org/1674-1056/21/i=9/a=097802

[68] C. Neto, D. R. Evans, E. Bonaccurso, H.-J. Butt, and V. S. Craig, "Boundary slip in newtonian liquids: a review of experimental studies," Reports on Progress in Physics, vol. 68, no. 12, pp. 2859

[69] M. T. Matthews and J. M. Hill, "Nanofluidics and the navier boundary condition," International Journal of Nanotechnology, vol. 5, no. 2-3, pp. 218-242

[70] Z. Li, C. Wei, J. Leung, Y. Wang, and H. Song, "Numerical and experimental study on gas flow in nanoporous media," Journal of Natural Gas Science and Engineering, vol. 27, pp. 738-744

[71] S. Whitaker, "Flow in porous media i: A theoretical derivation of darcy's law," Transport in porous media, vol. 1, no. 1, pp. 3-25 0169-3913, 1986.

[72] A. S. Ziarani and R. Aguilera, "Knudsen's permeability correction for tight porous media," Transport in porous media, vol. 91, no. 1, pp. 239-260

[73] X.-D. Shan and M. Wang, "Effective resistance of gas flow in microchannels," Advances in Mechanical Engineering, vol. 5, pp. 950681 1687-8140, 2013. 
[74] H. Song, Y. Wang, J. Wang, and Z. Li, "Unifying diffusion and seepage for nonlinear gas transport in multiscale porous media," Chemical Physics Letters, vol. 661, pp. 246-250

[75] T. G. Myers, "Why are slip lengths so large in carbon nanotubes?" Microfluidics and Nanofluidics, vol. 10, no. 5, pp. 1141-1145, 2011. [Online]. Available: https://doi.org/10.1007/s10404-010-0752-7

[76] P.-G. de Gennes, "On fluid/wall slippage," Langmuir, vol. 18, no. 9, pp. 3413-3414

[77] J. C. T. Eijkel and A. v. d. Berg, "Nanofluidics: what is it and what can we expect from it?" Microfluidics and Nanofluidics, vol. 1, no. 3, pp. 249-267, 2005. [Online]. Available: https://doi.org/10.1007/s10404-004-0012-9

[78] R. J. Ambrose, R. C. Hartman, M. Diaz Campos, I. Y. Akkutlu, and C. Sondergeld, "New pore-scale considerations for shale gas in place calculations," 2010.

[79] W. Wei and Y. Xia, "Geometrical, fractal and hydraulic properties of fractured reservoirs: A mini-review," Adv. Geo Energy, vol. 1, no. 1, pp. 31-38, 2017.

[80] Z. Tan, W. Wang, W. Li, S. Lu, and T. He, "Controlling factors and physical property cutoffs of the tight reservoir in the liuhe basin," ADVANCES IN GEOENERGY RESEARCH, vol. 1, pp. 190-202, 122017.

[81] S. Yinghao, H. Ge, X. Zhang, L. Chang, L. Dunqing, and J. Liu, "Impact of fracturing liquid absorption on the production and water-block unlocking for shale gas reservoir," ADVANCES IN GEO-ENERGY RESEARCH, vol. 2, pp. 163-172, 062018.

[82] J. Cai, W. Wei, X. Hu, R. Liu, and J. Wang, "Fractal characterization of dynamic fracture network extension in porous media," Fractals, vol. 25, no. 02, pp. 1750023

[83] N. G. Hadjiconstantinou, "The limits of navier-stokes theory and kinetic extensions for describing small-scale gaseous hydrodynamics," Physics of Fluids, vol. 18, no. 11 , pp. 111301

[84] C. V. . Heer, Statistical mechanics, kinetic theory, and stochastic processes. Elsevier, 2012.

[85] G. Bird, "Molecular gas dynamics and the direct simulation monte carlo of gas flows," Clarendon, Oxford, vol. 508, p. 128, 1994.

[86] J. Koplik and J. R. Banavar, "Continuum deductions from molecular hydrodynamics," Annual Review of Fluid Mechanics, vol. 27, no. 1, pp. 257-292

[87] A. Sharma, S. Namsani, and J. K. Singh, "Molecular simulation of shale gas adsorption and diffusion in inorganic nanopores," Molecular Simulation, vol. 41, no. 5-6, pp. $414-422$ 
[88] Z. Jin and A. Firoozabadi, "Flow of methane in shale nanopores at low and high pressure by molecular dynamics simulations," The Journal of Chemical Physics, vol. 143, no. 10, p. 104315, 2018/04/04 2015. [Online]. Available: https://doi.org/10.1063/1.4930006

[89] H. Wu, J. Chen, and H. Liu, "Molecular dynamics simulations about adsorption and displacement of methane in carbon nanochannels," The Journal of Physical Chemistry C, vol. 119, no. 24, pp. 13652-13657 2015.

[90] J. A. Thomas and A. J. H. McGaughey, "Water flow in carbon nanotubes: Transition to subcontinuum transport," Physical Review Letters, vol. 102, no. 18, pp. 184502-, 05 2009. [Online]. Available: https://link.aps.org/doi/10.1103/PhysRevLett.102.184502

[91] X. Yang and C. Zhang, Structure and diffusion behavior of dense carbon dioxide fluid in clay-like slit pores by molecular dynamics simulation, 05 2005, vol. 407.

[92] A. Botan, B. Rotenberg, V. Marry, P. Turq, and B. Noetinger, "Carbon dioxide in montmorillonite clay hydrates: thermodynamics, structure, and transport from molecular simulation," The Journal of Physical Chemistry C, vol. 114, no. 35, pp. 14962-14969

[93] R. T. Cygan, V. N. Romanov, and E. M. Myshakin, "Molecular simulation of carbon dioxide capture by montmorillonite using an accurate and flexible force field," The Journal of Physical Chemistry C, vol. 116, no. 24, pp. 13 079-13091

[94] M. Firouzi, E. C. Rupp, C. W. Liu, and J. Wilcox, "Molecular simulation and experimental characterization of the nanoporous structures of coal and gas shale," International Journal of Coal Geology, vol. 121, pp. 123-128, 2014. [Online]. Available: http://www.sciencedirect.com/science/article/pii/S0166516213002498

[95] Q. Yuan, X. Zhu, K. Lin, and Y.-P. Zhao, "Molecular dynamics simulations of the enhanced recovery of confined methane with carbon dioxide," Physical Chemistry Chemical Physics, vol. 17, no. 47, pp. 31 887-31 893, 2015.

[96] X. Zhang, L. Xiao, X. Shan, and L. Guo, "Lattice boltzmann simulation of shale gas transport in organic nano-pores," Scientific reports, vol. 4, pp. 4843

[97] L. Chen, L. Zhang, Q. Kang, H. S. Viswanathan, J. Yao, and W. Tao, "Nanoscale simulation of shale transport properties using the lattice boltzmann method: permeability and diffusivity," Scientific reports, vol. 5, pp. 8089

[98] H. Huang and X.-y. Lu, "Relative permeabilities and coupling effects in steady-state gas-liquid flow in porous media: A lattice boltzmann study," Physics of Fluids, vol. 21, no. 9, p. 092104, 2018/03/20 2009. [Online]. Available: https://doi.org/10.1063/1.3225144 
[99] E. Fathi and I. Y. Akkutlu, "Lattice boltzmann method for simulation of shale gas transport in kerogen," 2012.

[100] E. Fathi, A. Tinni, and I. Y. Akkutlu, Shale gas correction to Klinkenberg slip theory. Society of Petroleum Engineers, 2012.

[101] H. Song, M. Yu, W. Zhu, P. Wu, Y. Lou, Y. Wang, and J. Killough, "Numerical investigation of gas flow rate in shale gas reservoirs with nanoporous media," International Journal of Heat and Mass Transfer, vol. 80, pp. 626-635, 2015. [Online]. Available: http://www.sciencedirect.com/science/article/pii/S001793101400831X

[102] J. Ma, J. P. Sanchez, K. Wu, G. D. Couples, and Z. Jiang, "A pore network model for simulating non-ideal gas flow in micro- and nanoporous materials," Fuel, vol. 116, pp. 498-508, 2014. [Online]. Available: http://www.sciencedirect.com/science/article/pii/S0016236113007692

[103] T. Cao, Z. Song, S. Wang, X. Cao, Y. Li, and J. Xia, "Characterizing the pore structure in the silurian and permian shales of the sichuan basin, china," Marine and Petroleum Geology, vol. 61, pp. 140-150, 2015. [Online]. Available: http://www.sciencedirect.com/science/article/pii/S0264817214003754

[104] X. Huang, K. W. Bandilla, and M. A. Celia, "Multi-physics pore-network modeling of two-phase shale matrix flows," Transport in Porous Media, vol. 111, no. 1, pp. 123-141, 2016. [Online]. Available: https://doi.org/10.1007/s11242-015-0584-8

[105] K. Wua, X. Li, C. Guo, and Z. Chen, "Adsorbed gas surface diffusion and bulk gas transport in nanopores of shale reservoirs with real gas effect-adsorptionmechanical coupling," 2015.

[106] H. Darcy, "Les fontaines publiques de la ville de dijon (dalmont, paris, 1856)," Google Scholar, pp. 305-401, 2007.

[107] T. V. Nguyen, "Experimental study of non-darcy flow through perforations," 1986.

[108] L. Klinkenberg, The permeability of porous media to liquids and gases. American Petroleum Institute, 1941.

[109] F. O. Jones and W. Owens, "A laboratory study of low-permeability gas sands," Journal of Petroleum Technology, vol. 32, no. 09, pp. 1,631-1,640 0149-2136, 1980.

[110] K. Sampath and C. W. Keighin, "Factors affecting gas slippage in tight sandstones of cretaceous age in the uinta basin," Journal of Petroleum Technology, vol. 34, no. 11 , pp. $2,715-2,720$

[111] F. Civan, "Effective correlation of apparent gas permeability in tight porous media," Transport in porous media, vol. 82, no. 2, pp. 375-384 0169-3913, 2010. 
[112] A. Beskok and G. E. Karniadakis, "Report: a model for flows in channels, pipes, and ducts at micro and nano scales," Microscale Thermophysical Engineering, vol. 3, no. 1, pp. 43-77

[113] A. Sakhaee-Pour and S. Bryant, "Gas permeability of shale," 2012.

[114] W. Pollard and R. D. Present, "On gaseous self-diffusion in long capillary tubes," Physical Review, vol. 73, no. 7, p. 762, 1948.

[115] H. Sun, A. Chawathe, H. Hoteit, X. Shi, and L. Li, "Understanding shale gas flow behavior using numerical simulation," SPE Journal, vol. 20, no. 01, pp. 142-154

[116] Y. He, J. Cheng, X. Dou, and X. Wang, "Research on shale gas transportation and apparent permeability in nanopores," Journal of Natural Gas Science and Engineering, vol. 38, pp. 450-457, 2017. [Online]. Available: http://www.sciencedirect.com/science/article/pii/S1875510016309325

[117] B. Ghanbarian and F. Javadpour, "Upscaling pore pressure-dependent gas permeability in shales," Journal of Geophysical Research: Solid Earth, vol. 122, no. 4, pp. 2541-2552, 2017. [Online]. Available: https://agupubs.onlinelibrary.wiley.com/doi/abs/10.1002/2016JB013846

[118] D. Li and T. W. Engler, "Literature review on correlations of the non-darcy coefficient," 2001.

[119] H. Belhaj, K. Agha, A. Nouri, S. Butt, and M. Islam, Numerical and experimental modeling of non-Darcy flow in porous media. Society of Petroleum Engineers, 2003.

[120] D. Takhanov, "Forchheimer model for non-darcy flow in porous media and fractures," 2011.

[121] A. . Bejan, Convection heat transfer. John wiley sons, 2013.

[122] B. Lai, J. L. Miskimins, and Y.-S. Wu, "Non-darcy porous-media flow according to the barree and conway model: Laboratory and numerical-modeling studies," 2012 .

[123] A. Al-Otaibi and Y.-S. Wu, An alternative approach to modeling non-Darcy flow for pressure transient analysis in porous and fractured reservoirs. Society of Petroleum Engineers, 2011.

[124] Y.-S. Wu, B. Lai, J. L. Miskimins, P. Fakcharoenphol, and Y. Di, "Analysis of multiphase non-darcy flow in porous media," Transport in Porous Media, vol. 88, no. 2, pp. 205-223, 2011. [Online]. Available: https://doi.org/10.1007/s11242011-9735-8 
[125] R. D. Barree and M. Conway, "Multiphase non-darcy flow in proppant packs," 2007.

[126] B. Lai, J. L. Miskimins, and Y.-S. Wu, "Non-darcy porous-media flow according to the barree and conway model: Laboratory and numerical-modeling studies," 2012 .

[127] F. Javadpour, "Nanopores and apparent permeability of gas flow in mudrocks (shales and siltstone)," Journal of Canadian Petroleum Technology, vol. 48, no. 08, pp. $16-21$

[128] R. G. Loucks, R. M. Reed, S. C. Ruppel, and U. Hammes, "Spectrum of pore types and networks in mudrocks and a descriptive classification for matrix-related mudrock pores," AAPG bulletin, vol. 96, no. 6, pp. 1071-1098 0149-1423, 2012.

[129] M. E. Curtis, R. J. Ambrose, and C. H. Sondergeld, Structural characterization of gas shales on the micro-and nano-scales. Society of Petroleum Engineers, 2010.

[130] D. Jarvie, R. Pollastro, R. Hill, K. Bowker, B. Claxton, and J. Burgess, Evaluation of hydrocarbon generation and storage in the Barnett Shale, Ft. Worth Basin, Texas, 2004.

[131] I. D. Sulucarnain, C. H. Sondergeld, and C. S. Rai, An NMR study of shale wettability and effective surface relaxivity. Society of Petroleum Engineers, 2012.

[132] F. P. Wang and R. M. Reed, Pore networks and fluid flow in gas shales. Society of Petroleum Engineers, 2009.

[133] J. D. Hudson, F. Civan, G. Michel, D. Devegowda, and R. F. Sigal, Modeling multiple-porosity transport in gas-bearing shale formations. Society of Petroleum Engineers, 2012.

[134] B. Yan, Y. Wang, and J. E. Killough, "Beyond dual-porosity modeling for the simulation of complex flow mechanisms in shale reservoirs," Computational Geosciences, vol. 20, no. 1, pp. 69-91, 2016. [Online]. Available: https://doi.org/10.1007/s10596-015-9548-x

[135] Y.-S. Wu, G. J. Moridis, B. Bai, and K. Zhang, "A multi-continuum model for gas production in tight fractured reservoirs," 2009.

[136] D. Y. Ding, H. Langouët, and L. Jeannin, "Simulation of fracturing-induced formation damage and gas production from fractured wells in tight gas reservoirs," SPE Production Operations, vol. 28, no. 03, pp. 246-258

[137] D. Y. Ding, Y. Wu, and L. Jeannin, "Efficient simulation of hydraulic fractured wells in unconventional reservoirs," Journal of Petroleum Science and Engineering, vol. 122 , pp. $631-642$ 
[138] C. Clarkson and T. Ertekin, A new model for shale gas matrix flow using the dynamic-slippage concept, 2010.

[139] M. E. Curtis, C. H. Sondergeld, R. J. Ambrose, and C. S. Rai, "Microstructural investigation of gas shales in two and three dimensions using nanometer-scale resolution imagingmicrostructure of gas shales," $A A P G$ bulletin, vol. 96, no. 4, pp. $665-677$

[140] A. S. Ziarani and R. Aguilera, "Knudsen's permeability correction for tight porous media," Transport in porous media, vol. 91, no. 1, pp. 239-260

[141] C. Guo, M. Wei, and H. Liu, "Study of gas production from shale reservoirs with multi-stage hydraulic fracturing horizontal well considering multiple transport mechanisms," PLoS ONE, vol. 13, no. 1, p. e0188480, 2018. [Online]. Available: http://www.ncbi.nlm.nih.gov/pmc/articles/PMC5761844/

[142] R. H. Dean, X. Gai, C. M. Stone, and S. E. Minkoff, "A comparison of techniques for coupling porous flow and geomechanics," 2006.

[143] W. M. F. and G. Xiuli, "Iteratively coupled mixed and galerkin finite element methods for poro-elasticity," Numerical Methods for Partial Differential Equations, vol. 23, no. 4, pp. 785-797, 2018/03/18 2007. [Online]. Available: https://doi.org/10.1002/num.20258

[144] F. O. Alpak, "Robust fully-implicit coupled multiphase-flow and geomechanics simulation," 2015.

[145] J. Cai and B. Yu, "A discussion of the effect of tortuosity on the capillary imbibition in porous media," Transport in Porous Media, vol. 89, no. 2, pp. 251-263, 2011. [Online]. Available: https://doi.org/10.1007/s11242-011-9767-0

[146] J. Cai, B. Yu, M. Zou, and L. Luo, "Fractal characterization of spontaneous co-current imbibition in porous media," Energy \&3 Fuels, vol. 24, no. 3, pp. 1860-1867, 03 2010. [Online]. Available: https://doi.org/10.1021/ef901413p

[147] W. Guo, Z. Hu, X. Zhang, R. Yu, and L. Wang, "Shale gas adsorption and desorption characteristics and its effects on shale permeability," Energy Exploration \& Exploitation, vol. 35, no. 4, pp. 463-481, 2018/03/25 2017. [Online]. Available: https://doi.org/10.1177/0144598716684306

[148] S. E. Minkoff, C. M. Stone, S. Bryant, M. Peszynska, and M. F. Wheeler, "Coupled fluid flow and geomechanical deformation modeling," Journal of Petroleum Science and Engineering, vol. 38, no. 1, pp. 37-56, 2003. [Online]. Available: http://www.sciencedirect.com/science/article/pii/S0920410503000214

[149] X. Guo, H. Song, K. Wu, and J. Killough, "Pressure characteristics and performance of multi-stage fractured horizontal well in shale gas 
reservoirs with coupled flow and geomechanics," Journal of Petroleum Science and Engineering, vol. 163, pp. 1-15, 2018. [Online]. Available: http://www.sciencedirect.com/science/article/pii/S0920410517309956

[150] J. Gupta, M. Zielonka, R. A. Albert, A. M. El-Rabaa, H. A. Burnham, and N. H. Choi, "Integrated methodology for optimizing development of unconventional gas resources," 2012.

[151] W. Yu, Z. Luo, F. Javadpour, A. Varavei, and K. Sepehrnoori, "Sensitivity analysis of hydraulic fracture geometry in shale gas reservoirs," Journal of Petroleum Science and Engineering, vol. 113, pp. 1-7, 2014. [Online]. Available: http://www.sciencedirect.com/science/article/pii/S0920410513003537

[152] M. Moradi, F. Imani, H. Naji, S. Moradi Behbahani, and M. Taghi Ahmadi, Variation in soil carbon stock and nutrient content in sand dunes after afforestation by Prosopis juliflora in the Khuzestan province (Iran), 05 2017, vol. 10.

[153] C. An, Y. Fang, S. Liu, M. Alfi, B. Yan, Y. Wang, and J. Killough, Impacts of Matrix Shrinkage and Stress Changes on Permeability and Gas Production of Organic-Rich Shale Reservoirs, 052017.

[154] I. Shovkun and D. N. Espinoza, "Coupled fluid flow-geomechanics simulation in stress-sensitive coal and shale reservoirs: Impact of desorption-induced stresses, shear failure, and fines migration," Fuel, vol. 195, pp. 260-272, 2017. [Online]. Available: http://www.sciencedirect.com/science/article/pii/S0016236117300650

[155] C. Wei, L. Wang, B. Li, L. Xiong, S. Liu, J. Zheng, S. Hu, and H. Song, A Study of Nonlinear Elasticity Effects on Permeability of Stress Sensitive Shale Rocks Using an Improved Coupled Flow and Geomechanics Model: A Case Study of the Longmaxi Shale in China, 02 2018, vol. 11.

[156] V. Shabro, C. Torres-Verdín, F. Javadpour, and K. Sepehrnoori, "Finite-difference approximation for fluid-flow simulation and calculation of permeability in porous media," Transport in porous media, vol. 94, no. 3, pp. 775-793

[157] E. Nacul, C. Lepretre, O. Pedrosa Jr, P. Girard, and K. Aziz, Efficient use of domain decomposition and local grid refinement in reservoir simulation. Society of Petroleum Engineers, 1990.

[158] T. Ertekin, J. H. Abou-Kassen, and G. R. . King, Basic applied reservoir simulations. Society of Petroleum Engineers, 2001.

[159] A. . . Firoozabadi, Thermodynamics of hydrocarbon reservoirs. McGraw-Hill, 1999. 
[160] R. Jayakumar, V. Sahai, and A. Boulis, A better understanding of finite element simulation for shale gas reservoirs through a series of different case histories. Society of Petroleum Engineers, 2011.

[161] R. Logan, R. Lee, and M. Tek, Microcomputer gas reservoir simulation using finite element methods. Society of Petroleum Engineers, 1985.

[162] G. J. Moridis, T. A. Blasingame, and C. M. Freeman, Analysis of mechanisms of flow in fractured tight-gas and shale-gas reservoirs. Society of Petroleum Engineers, 2010.

[163] K. Aziz and A. . Settari, Petroleum reservoir simulation. Chapman Hall, 1979.

[164] Z. Heinemann, C. Brand, M. Munka, and Y. Chen, Modeling reservoir geometry with irregular grids. Society of Petroleum Engineers, 1989.

[165] L. Zhang, D. Li, L. Wang, and D. Lu, "Simulation of gas transport in tight/shale gas reservoirs by a multicomponent model based on pebi grid," Journal of Chemistry, vol. 2015

[166] J. Sun, D. Schechter, and C.-K. Huang, "Grid-sensitivity analysis and comparison between unstructured perpendicular bisector and structured tartan/local-gridrefinement grids for hydraulically fractured horizontal wells in eagle ford formation with complicated natural fractures," 2016.

[167] Y. Yang, S. Fu, and E. T. Chung, "Online mixed multiscale finite element method with oversampling and its applications," arXiv preprint arXiv:180\%.00\%10, 2018.

[168] E. T. Chung, Y. Efendiev, and W. T. Leung, "Residual-driven online generalized multiscale finite element methods," Journal of Computational Physics, vol. 302, pp. $176-190$

[169] M. Alotaibi, V. M. Calo, Y. Efendiev, J. Galvis, and M. Ghommem, "Global-local nonlinear model reduction for flows in heterogeneous porous media," Computer Methods in Applied Mechanics and Engineering, vol. 292, pp. 122-137

[170] X. Chen, G. Yao, J. Cai, Y. Huang, and X. Yuan, "Fractal and multifractal analysis of different hydraulic flow units based on micro-ct images," Journal of Natural Gas Science and Engineering, vol. 48, pp. 145-156

[171] Y. Efendiev and T. Y. Hou, Multiscale finite element methods: theory and applications. Springer Science Business Media, 2009, vol. 4

[172] I. Babuška, G. Caloz, and J. E. Osborn, "Special finite element methods for a class of second order elliptic problems with rough coefficients," SIAM Journal on Numerical Analysis, vol. 31, no. 4, pp. 945-981 0036-1429, 1994. 
[173] T. Arbogast, "Implementation of a locally conservative numerical subgrid upscaling scheme for two-phase darcy flow," Computational Geosciences, vol. 6, no. 3-4, pp. $453-481$

[174] Z. Chen and T. Hou, "A mixed multiscale finite element method for elliptic problems with oscillating coefficients," Mathematics of Computation, vol. 72, no. 242, pp. 541-576

[175] T. Arbogast, G. Pencheva, M. F. Wheeler, and I. Yotov, "A multiscale mortar mixed finite element method," Multiscale Modeling Simulation, vol. 6, no. 1, pp. 319-346

[176] O. Møyner and K.-A. Lie, "A multiscale restriction-smoothed basis method for high contrast porous media represented on unstructured grids," Journal of Computational Physics, vol. 304, pp. 46-71, 2016. [Online]. Available: http://www.sciencedirect.com/science/article/pii/S0021999115006725

[177] P. Vanek, J. Mandel, and M. Brezina, "Algebraic multigrid on unstructured meshes," University of Colorado at Denver, UCD = CCM Report, no. 34, 1994.

[178] P. Vaněk, J. Mandel, and M. Brezina, "Algebraic multigrid by smoothed aggregation for second and fourth order elliptic problems," Computing, vol. 56, no. 3, pp. $179-196$

[179] M. Brezina, R. Falgout, S. MacLachlan, T. Manteuffel, S. McCormick, and J. Ruge, "Adaptive smoothed aggregation ( sa) multigrid," SIAM review, vol. 47, no. 2, pp. $317-346$

[180] K. Stüben, A review of algebraic multigrid. Elsevier, 2001, pp. 281-309.

[181] M. W. Gee, C. M. Siefert, J. J. Hu, R. S. Tuminaro, and M. G. Sala, "Ml 5.0 smoothed aggregation user's guide," Tech. Rep., 2006.

[182] N. C. Reis Jr, J. P. De Angeli, A. F. de Souza, and R. H. Lopes, "Petroleum reservoir simulation using finite volume method with non-structured grids and parallel distributed computing," 2001.

[183] A. Datta-Gupta, J. Xie, N. Gupta, M. J. King, and W. J. Lee, "Radius of investigation and its generalization to unconventional reservoirs," Journal of Petroleum Technology, vol. 63, no. 07, pp. 52-55 0149-2136, 2011.

[184] J. Xie, C. Yang, N. Gupta, M. J. King, and A. Datta-Gupta, "Integration of shalegas-production data and microseismic for fracture and reservoir properties with the fast marching method," SPE Journal, vol. 20, no. 02, pp. 347-359

[185] J. Xie, N. Gupta, M. J. King, and A. Datta-Gupta, "Depth of investigation and depletion behavior in unconventional reservoirs using fast marching methods," 2012 . 
[186] Y. Zhang, C. Yang, M. J. King, and A. Datta-Gupta, "Fast-marching methods for complex grids and anisotropic permeabilities: Application to unconventional reservoirs," 2013.

[187] J. A. Sethian, Level set methods and fast marching methods: evolving interfaces in computational geometry, fluid mechanics, computer vision, and materials science. Cambridge university press, 1999, vol. 3

[188] A. Datta-Gupta and M. J. King, Streamline simulation: theory and practice. Society of Petroleum Engineers Richardson, 2007, vol. 11.

[189] A. Datta-Gupta, J. Xie, N. Gupta, M. J. King, and W. J. Lee, "Radius of investigation and its generalization to unconventional reservoirs," 2011. 